\title{
Investigation of the cleaning of egg yolk deposits from tank surfaces using continuous and pulsed flows
}

Yang, Jifeng; Kjellberg, Kim; Jensen, Bo Boye Busk; Nordkvist, Mikkel; Gernaey, Krist V.; Krühne, Ulrich

Published in:

Food and Bioproducts Processing

Link to article, DOI:

10.1016/j.fbp.2018.10.007

Publication date:

2019

Document Version

Peer reviewed version

Link back to DTU Orbit

Citation (APA):

Yang, J., Kjellberg, K., Jensen, B. B. B., Nordkvist, M., Gernaey, K. V., \& Krühne, U. (2019). Investigation of the cleaning of egg yolk deposits from tank surfaces using continuous and pulsed flows. Food and Bioproducts Processing, 113, 154-167. https://doi.org/10.1016/j.fbp.2018.10.007

\section{General rights}

Copyright and moral rights for the publications made accessible in the public portal are retained by the authors and/or other copyright owners and it is a condition of accessing publications that users recognise and abide by the legal requirements associated with these rights.

- Users may download and print one copy of any publication from the public portal for the purpose of private study or research.

- You may not further distribute the material or use it for any profit-making activity or commercial gain

- You may freely distribute the URL identifying the publication in the public portal 


\section{Accepted Manuscript}

Title: Investigation of the cleaning of egg yolk deposits from tank surfaces using continuous and pulsed flows

Authors: Jifeng Yang, Kim Kjellberg, Bo Boye Busk Jensen, Mikkel Nordkvist, Krist V. Gernaey, Ulrich Krühne

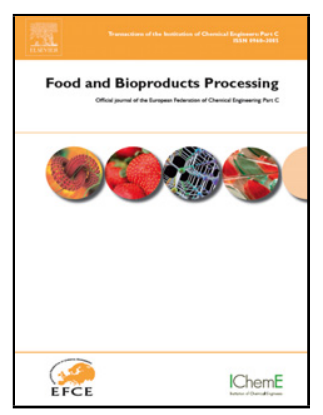

PII:

S0960-3085(18)30455-3

DOI: https://doi.org/10.1016/j.fbp.2018.10.007

Reference: FBP 1004

To appear in: Food and Bioproducts Processing

Received date: 17-7-2018

Revised date: $14-9-2018$

Accepted date: $10-10-2018$

Please cite this article as: Yang, Jifeng, Kjellberg, Kim, Jensen, Bo Boye Busk, Nordkvist, Mikkel, Gernaey, Krist V., Krühne, Ulrich, Investigation of the cleaning of egg yolk deposits from tank surfaces using continuous and pulsed flows.Food and Bioproducts Processing https://doi.org/10.1016/j.fbp.2018.10.007

This is a PDF file of an unedited manuscript that has been accepted for publication. As a service to our customers we are providing this early version of the manuscript. The manuscript will undergo copyediting, typesetting, and review of the resulting proof before it is published in its final form. Please note that during the production process errors may be discovered which could affect the content, and all legal disclaimers that apply to the journal pertain. 


\title{
Investigation of the cleaning of egg yolk deposits from tank surfaces using continuous and pulsed flows
}

\author{
Jifeng Yang ${ }^{\mathrm{a}}$, Kim Kjellberg ${ }^{\mathrm{b}}$, Bo Boye Busk Jensen ${ }^{\mathrm{b}}$, Mikkel Nordkvist ${ }^{\mathrm{b}}$, Krist V. Gernaey ${ }^{\mathrm{a}}$, Ulrich Krühne ${ }^{\mathrm{a} *}$ \\ ${ }^{a}$ Process and Systems Engineering Center (PROSYS), Department of Chemical and Biochemical Engineering, \\ Technical University of Denmark, Søltofts Plads, Building 229, 2800 Kgs. Lyngby, Denmark
}

${ }^{\mathrm{b}}$ Alfa Laval Copenhagen A/S, Maskinvej 5, 2860 Søborg, Denmark

* Corresponding author: ulkr@kt.dtu.dk

\section{Highlights}

- Cleaning tank surface using pulsed flow improves cleaning efficiency.

- High alkali concentration results in less removal of egg yolk soil.

- $\quad$ Economic benefits using pulsed flow are found.

- Observations in pilot-scale applies in scale-up tests.

\section{Abstract}

This work examined the effects of burst or pulsed flows on the cleaning of tank surfaces soiled by egg yolk, under alkaline conditions, using a single axis rotary spray head. Firstly, four cleaning approaches (continuous flow without pre-wetting, continuous flow with pre-wetting, pulsed flow with a shorter period, pulsed flow with a longer period) were tested on a pilot-scale tank to clean both uncooked and cooked fouling materials. The effects of temperature, flow rate and alkali concentration were investigated. The results show that pulsed flows improve cleaning behavior, where pulsing with a shorter period and higher frequency results in the most deposit removal at the same detergent consumption. The impact of pre-wetting is less significant under the investigated conditions. Some findings are consistent with earlier reports, stating that higher temperature and flow rate improve cleaning by reducing cleaning time. An optimal alkali concentration exists, which is in line with results reported by other researchers when investigating other protein soil types. The economic benefits by using pulsed flow cleaning were 
discussed. Then, scale-up tests confirmed that the enhancement of cleaning by using pulsed flow with short period and high frequency could also apply in an industry-scale tank.

\section{Keywords}

Cleaning-in-place; tank cleaning; pulsed flow; burst cleaning; egg yolk 


\section{Introduction}

Fouling is the unwanted deposit build-up on a surface due to the adhesion of species to the surface as well as the cohesion between elements of the materials (Palabiyik et al., 2015). Cleaning fouling deposits is a significant process step in many food industries to reduce cross contamination risks and guarantee product quality. Minimizing the consumption of resources (water, chemical and electrical energy, etc.) is of great importance due to stricter legislative and environmental regulations (Tukker et al., 2006).

In some industries, i.e. brewery and dairy, cleaning of tanks contributes considerably to the overall cleaning costs and downtime. Cleaning of the internal tank surface is primarily performed by an automated cleaning-in-place (CIP) procedure with help of a cleaning device (i.e. static spray ball, rotary spray head or rotary jet head) to distribute cleaning liquid on the surface (Goode et al., 2013; Tamime, 2008). The mechanisms of tank cleaning are currently empirically described. Four models exist for describing the modes of soil removal from tank surfaces (Bhagat et al., 2017): dissolution moves soluble components to the cleaning solution through convective mass transfer; roll-up deforms insoluble and strong cohesive soils and causes them to leave the surface; erosion detaches weak cohesive soils layer after layer by local shear force; peeling isolates the soils with weak adhesive force as a layer. The key factors affecting the tank cleaning efficiency include chemical reaction, mechanical force, time, temperature and flow coverage (Tamime, 2008).

Burst, or pulsed, cleaning is an efficient practice in tank cleaning that is performed by interrupting a continuous flow with several breaks between shots of detergent. For tank cleaning, the term burst identifies the rectangular form of a pulse, meaning a two-level output of flow rate. Burst cleaning has been widely used when cleaning brewery fermenters to remove foam and yeast deposit that remain on the wall after emptying the tank. In this technique, the water pre-rinse step that is customary in continuous cleaning is skipped. Instead, a burst of alkali solution is applied for wetting the soils followed by a pause to allow the detergent to react. This sequence is repeated several times. It is reported that burst cleaning is able to reduce water and chemical consumption at the expense of longer cleaning time (Briggs et al., 2004; Kjellberg, 2016; Tamime, 2008). However, the mechanisms behind the improvement of tank cleaning by using burst or pulsed flows are still poorly understood, because a standardized method for assessing the tank cleaning performance is lacking (Stenby et al., 2012).

The scientific literature have discussed how pulsed flows enhance the cleaning of denatured whey protein deposits in pipes (Gillham et al., 2000) and annular tube heat exchangers (Bode et al., 2005). Reduced chemical consumption was also found by exposing deposits to a cleaning chemical environment before water rinse (Christian and Fryer, 2006). Computational fluid dynamics (CFD) studies (Augustin et al., 2010; Föste et al., 2013; Jensen, 2007) and the analytical approaches using Fourier series (Celnik et al., 2005) prove that the alteration of 
flow pattern, particularly flow reversal, enhances the local wall shear stress and hence increases the cleaning efficiency. Furthermore, pulsed flow has been observed to play an positive role in the cleaning of filter media (Olayiwola and Walzel, 2009; Weidemann et al., 2014). For the cleaning of open surfaces, enhanced cleaning performance has been found for detaching xanthan soil from vertical surfaces using pulsed water jets (Fuchs et al., 2017; Stoye et al., 2014).

However, implementing pulsed flows in tank cleaning operations differs from the processes investigated in the aforementioned studies. Firstly, the pulse technique used in tank cleaning is regularly performed by controlling the pump on or off rather than hydraulically generating a sinusoidal flow rate. The frequency (around $1 \mathrm{~Hz}$ ) of changing the flow rate in the above-mentioned researches is extremely high for cleaning a tank, because the water flow coming from a jet device takes a period to reach the tank surface with stabilized high impact force. Secondly, the soils are soaked in the cleaning liquid environment between pulses when cleaning pipes, heat exchangers or filters. However, when cleaning a tank, the flow is one-way and most of the cleaning liquid flows downwards under gravity. Thirdly, changing flow rate affects the performance of rotating cleaning devices since the rotational speed is dependent on the flow rate of liquid through the machine. The duration of each burst should ensure that all areas are covered by cleaning liquid. In addition, the damage to pumps as a result of frequent startup and shutdown has not been fully determined yet (Goode et al., 2013).

The aim of this work is to compare the cleaning of tank surfaces soiled by egg yolk using continuous or pulsed flows. Different process parameters (temperature, flow rate and chemical concentration) were investigated. The primary goal of using pulsed flow to clean tank surfaces is to reduce liquid consumption and henceforth to reduce cleaning cost and environmental influence. In the end, this work provides a quantitative measure of performance to compare the cleaning results by using pulsed flows or conventional continuous flows.

\section{Materials and Methods (Pilot-scale)}

\subsection{Experiment setup}

The experiments were performed in a pilot-scale CIP system, as shown in Figure 1, consisting of two storage tanks: one for alkali solution and one for water. The test tank was made from transparent polyvinyl chloride (PVC) with $50 \mathrm{~cm}$ diameter, $55 \mathrm{~cm}$ height and $10 \mathrm{~cm}$ additional depth of a klopper torispherical bottom. Soiling materials were deposited on an extra soft stainless steel plate (type 304, roughness values $R a 0.17 \pm 0.02 \mu \mathrm{m}, 52 \mathrm{~cm}$ height, 30 $\mathrm{cm}$ width), which was dried in an oven before being bent and mounted along the tank wall by two separated supports. Cleaning was performed using a single axis rotary spray head. As illustrated in Figure 2, the rotary spray 
head was located in the upper section of the tank, resulting in the cleaning liquid distributing with a rotating fan. A digital camera was used to take pictures of the test plate during cleaning.

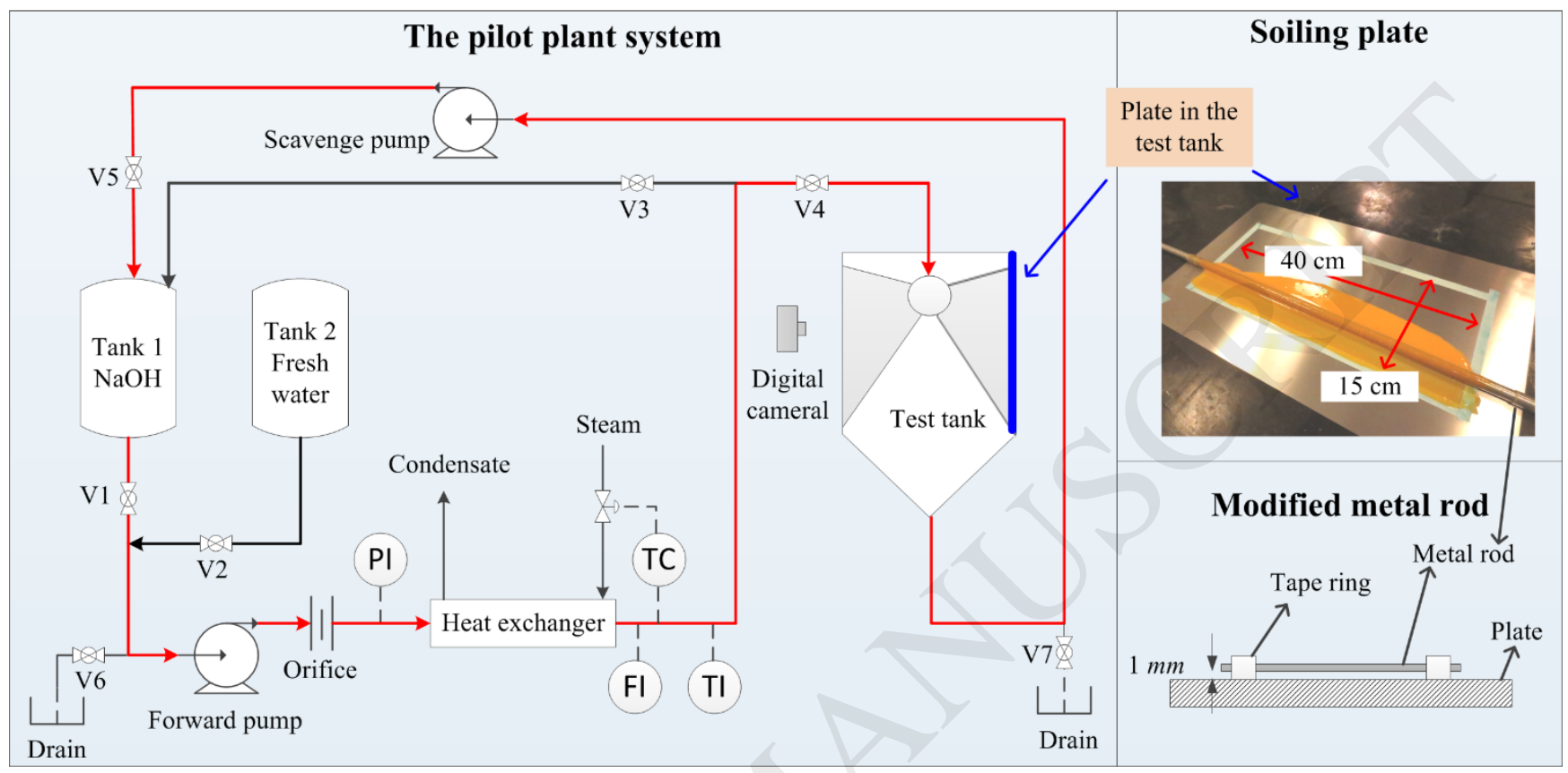

Figure 1 Schematic diagram of the pilot-scale setup, the soiling plate and the modified metal rod. 


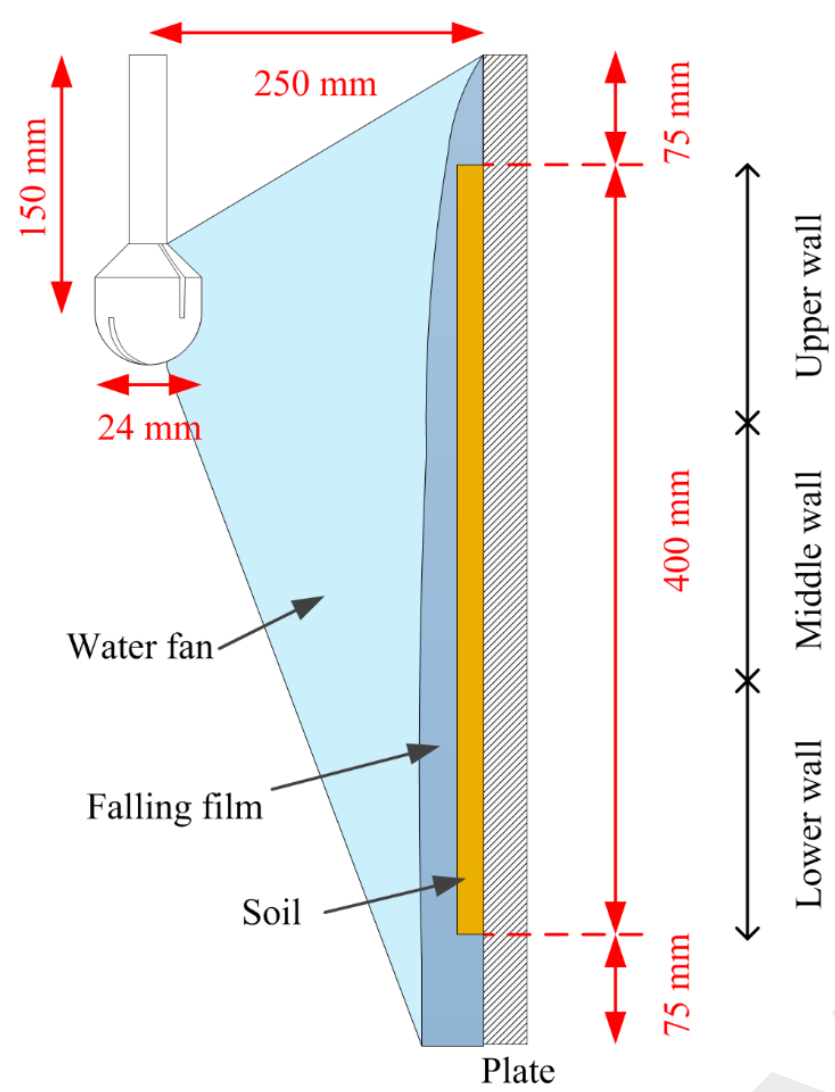

Figure 2 Illustration of cleaning by a rotary spray head. The surface is divided into upper, middle and lower wall sections for analysis.

\subsection{Soiling and cleaning}

Pasteurized egg yolk (Hedegaard, Denmark) was selected as the model soil in all experiments. Per $100 \mathrm{~g}$, the soil contained $13 \mathrm{~g}$ protein, $24 \mathrm{~g}$ fat, $0.3 \mathrm{~g}$ carbohydrate and $0.1 \mathrm{~g}$ salt. Egg yolk belongs to the type 3 soil according to the classification of Fryer et al. (2011), meaning chemical cleaning is required to completely remove organic films. The soil was mixed with $1 \% \mathrm{w} / \mathrm{w}$ riboflavin (Sigma-Aldrich, US) to improve visual inspection of the cleaning efficiency. Only the center plate area of $40 \times 15 \mathrm{~cm}^{2}$ was covered by soil materials. An even layer was achieved by spreading the soil material using a modified straight metal rod, which had been wrapped with tapes to form a $1 \mathrm{~mm}$ thickness ring on each end so a uniform layer could be obtained under the rod after spreading (Figure 1). The soiled plate was then dried in an oven with hot air to form uncooked ( 40 - $45^{\circ} \mathrm{C}$ for 2 hours) or cooked $\left(80-90^{\circ} \mathrm{C}\right.$ for 1 hour) soils before being mounted on the tank wall prior to cleaning. The protein structure of egg yolk was reported to aggregate when being heated up to $70{ }^{\circ} \mathrm{C}$ (Denmat et al., 1999; Perez-Mohedano et al., 2016). The plates were weighed before and after soiling, obtaining $16.8 \pm 1.2 \mathrm{~g}$ uncooked soil or $16.4 \pm 1.1 \mathrm{~g}$ cooked soil per plate, respectively. The variation of mass was within the range of $\pm 7 \%$. 
The cleaning procedure consisted of 10 min circulation of $\mathrm{NaOH}$ solution and 1 min final rinse with fresh water. The circulation of $\mathrm{NaOH}$ solution was performed according to four different approaches, as described in Figure 3:

- Continuous flow $\left(C_{1}\right)$ : continuous $10 \mathrm{~min}$ flow before $1 \mathrm{~min}$ final rinse. The total cleaning time was $11 \mathrm{~min}$.

- Pulsed flow with a period of $60 \mathrm{~s}\left(P_{l}\right): 30 \mathrm{~s}$ flow followed by $30 \mathrm{~s}$ break repeated 20 times before final rinse. The total cleaning time was $21 \mathrm{~min}$.

- Pulsed flow with a period of $4 \mathrm{~min}\left(P_{2}\right): 2 \mathrm{~min}$ flow followed by $2 \mathrm{~min}$ break repeated 5 times prior to final rinse, with a total cleaning time of $21 \mathrm{~min}$.

- Continuous flow with pre-wetting $\left(C_{2}\right)$ : $30 \mathrm{~s}$ flow followed by $10 \mathrm{~min}$ break and $9.5 \mathrm{~min}$ continuous flow before final rinse. The total cleaning time was $21 \mathrm{~min}$.

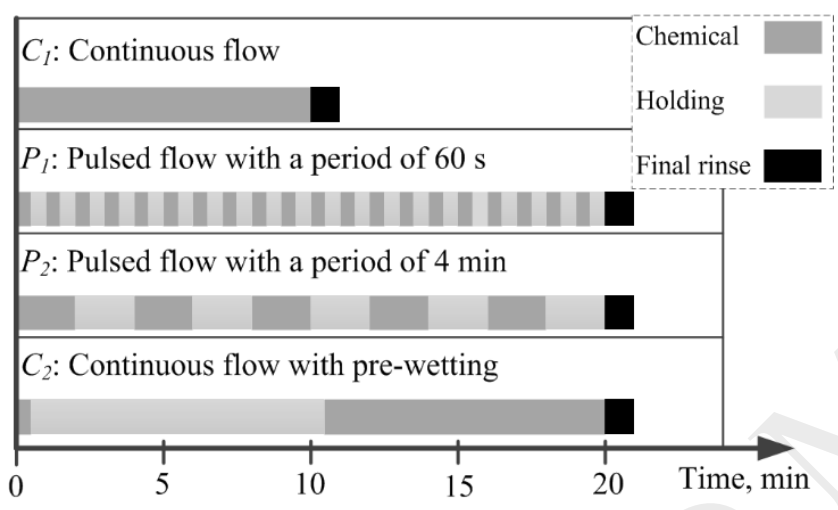

Figure 3 Four cleaning approaches applied in this study.

The cleaning results were evaluated by taking a photo of the test plate during each break and after final rinse. The first two approaches $C_{1}$ and $P_{1}$ were mainly studied, and $C_{2}$ and $P_{2}$ were designed for comparisons. The burst frequency of $P_{2}$ was more similar to the common industrial practices for tank cleanings. To reduce the damage to pumps caused by frequent startup, the forward flow was controlled by alternatively opening or closing the butterfly valves V3 and V4, resulting in the switch between flow circulation (during breaks) and cleaning. The scavenge pump started when the liquid was accumulated at the test tank bottom above a certain level. The examined parameters included temperature, flow rate and $\mathrm{NaOH}$ concentration, which are described in section 2.4. All experiments were performed at least in duplicates.

\subsection{Determination of soiling areas}

The remaining soiling areas were calculated with help of the image analysis toolbox in Matlab (MathWorks, US). The normalized remaining soiling area $y$ was defined as the ratio of the remaining soiling area to the total area, according to: 


$$
y=\frac{\text { Remaining soiling area }}{\text { Total soiling area before cleaning }}
$$

So $y=1$ denotes completely dirty and $y=0$ denotes completely clean. The soiled plate was equally divided into three sections (upper wall, middle wall and lower wall) with $13.33 \mathrm{~cm}$ height for each, as shown in Figure 2. The different sections were analyzed separately.

\subsection{Factorial experimental design}

As shown in Table 1, the influence of temperature $T$, flow rate $F R$ and $\mathrm{NaOH}$ concentration $C$ were evaluated in terms of the normalized remaining soiling area $y$. The experiments were executed in a random order to randomize experimental errors (Montgomery, 2012). A second-order regression model for the actual variables $x_{i}$ (indicating $T, F R$ and $C$ ) was obtained by fitting the experimental data based on the factors and interaction effects as follows:

$$
\hat{y}=\beta_{0}+\sum_{j=1}^{3} \beta_{j} x_{j}+\sum_{j=1}^{3} \sum_{i<j} \beta_{i j} x_{i} x_{j}+\epsilon
$$

where $\hat{y}$ is the predicted value of $y . \beta_{0}, \beta_{i}$ and $\beta_{i j}$ are the intercept, linear and interaction terms respectively and $\epsilon$ is the statistical error term. Adding one center point in the factorial experimental design helped to examine the significance of curvature effects on the model if a $\beta_{i i} x_{i}^{2}$ term was added.

\begin{tabular}{|c|c|c|c|c|c|c|}
\hline \multirow[b]{2}{*}{ Runs } & \multicolumn{3}{|c|}{ Coded levels of variables } & \multicolumn{3}{|c|}{ Actual levels of variables } \\
\hline & $\begin{array}{c}\text { Temperature } \\
X_{1}\end{array}$ & $\begin{array}{c}\text { Flow rate } \\
X_{2}\end{array}$ & $\begin{array}{c}\text { Concentration } \\
\qquad X_{3}\end{array}$ & $\begin{array}{c}\text { Temperature } \\
T,\left[{ }^{\circ} \mathrm{C}\right]\end{array}$ & $\begin{array}{c}\text { Flow rate } \\
F R,\left[\mathrm{~m}^{3} / \mathrm{h}\right]\end{array}$ & $\begin{array}{c}\text { Concentration } \\
C,\left[\mathrm{~kg} / \mathrm{m}^{3}\right]\end{array}$ \\
\hline \multicolumn{7}{|c|}{ Factorial points } \\
\hline 1 & -1 & -1 & -1 & 25 & 0.9 & 1 \\
\hline 2 & 1 & -1 & -1 & 55 & 0.9 & 1 \\
\hline 3 & -1 & 1 & -1 & 25 & 1.5 & 1 \\
\hline 4 & 1 & 1 & -1 & 55 & 1.5 & 1 \\
\hline 5 & -1 & -1 & 1 & 25 & 0.9 & 5 \\
\hline 6 & 1 & -1 & 1 & 55 & 0.9 & 5 \\
\hline 7 & -1 & 1 & 1 & 25 & 1.5 & 5 \\
\hline 8 & 1 & 1 & 1 & 55 & 1.5 & 5 \\
\hline \multicolumn{7}{|c|}{ Center point } \\
\hline 9 & 0 & 0 & 0 & 40 & 1.2 & 3 \\
\hline
\end{tabular}

Table $12^{3}$ factorial experiment design indicating the coded and actual values of variables 


\subsection{Cost model}

The total costs of cleaning by alkali solution $\left(\delta_{\text {Total }}\right)$ were found as the sum of the costs of fresh water $\left(\delta_{\text {Fresh water }}\right)$, chemical $\left(\delta_{\text {Chemical }}\right)$, electricity by pumps $\left(\delta_{\text {Electricity }}\right)$ and sensible heat $\left(\delta_{\text {Heat }}\right)$. To calculate the cleaning cost that results in a certain amount of cleanliness, the following equation was used:

$$
\frac{\text { Cleaning costs }}{\text { Degree of cleaning }}=\frac{\delta_{\text {Total }}}{100-99 \cdot \tilde{y}}=\frac{\delta_{\text {Fresh water }}+\delta_{\text {Chemical }}+\delta_{\text {Electricity }}+\delta_{\text {Heat }}}{100-99 \cdot \tilde{y}}
$$

where $\tilde{y}$ was the corrected term of $\hat{y}$ by eliminating the unrealistic prediction errors as:

$$
\tilde{y}=\left\{\begin{array}{cc}
0 & \hat{y}<0 \\
\hat{y} & 0 \leq \hat{y} \leq 1 \\
1 & \hat{y}>1
\end{array}\right.
$$

A degree of cleaning (DoC) value of 100 represents that all soils are removed, and the value of 1 represents that no soil is removed. The costs of fresh water, chemical, electricity and sensible heat were calculated by equations $5-8$, noting the term $t / 3600$ converts the time unit from seconds to hours:

$$
\begin{array}{cr}
\delta_{\text {Fresh water }}=F R \cdot t / 3600 \cdot \varphi_{\text {Water }} & 5 \\
\delta_{\text {Chemical }}=F R \cdot t / 3600 \cdot C \cdot \varphi_{\text {Chemical }} & 6 \\
\delta_{\text {Electricity }}=\left(P_{f}+P_{S}\right) \cdot t / 3600 \cdot \varphi_{\text {Electricity }} & 7 \\
\delta_{\text {Heat }}=F R \cdot t / 3600 \cdot \rho \cdot c_{P} \cdot\left(T-T_{0}\right) \cdot \varphi_{\text {Heat }} & 8
\end{array}
$$

where $P_{f}$ and $P_{S}$ are the powers of the forward and scavenge pumps, $\rho\left(1000 \mathrm{~kg} / \mathrm{m}^{3}\right)$ is the density of water, $c_{P}\left(4185.5 \mathrm{~J} / \mathrm{kg}{ }^{\circ} \mathrm{C}\right)$ is the heat capacity of water and $T_{0}\left(25^{\circ} \mathrm{C}\right)$ is room temperature. The unit cost of each item was selected based on the prices in Danish industries: $\varphi_{\text {Water }}=3.6$ Euro $/ \mathrm{m}^{3}$ including wastewater treatment, $\varphi_{\text {Chemical }}=1$ Euro $/ \mathrm{kg}, \varphi_{\text {Electricity }}=0.09$ Euro $/ \mathrm{kW} \cdot \mathrm{h}, \varphi_{\text {Heat }}=2.6 \times 10^{-8}$ Euro $/ \mathrm{J}$.

\section{Results and discussions}

\subsection{Cleaning dynamics}

Figure 4 shows the normalized remaining soiling area (of selected runs in Table 1, the results for all runs are displayed in Appendix Figure A1) at different wall locations by using continuous flow $C_{l}$ and pulsed flow $P_{l}$. At the same effective time, there are fewer soils remaining in the upper wall section than in the lower wall section, 
meaning that the fastest removal of deposit occurs in the upper part. As shown in Figure 2, the upper section is the closest to the rotary spray head and experiences the highest impact force from the droplets in the liquid fan. However, a thicker falling film is the result in the lower section since the liquid flows down due to the gravity, implying higher wall shear stress in the lower section than in the upper section. The phenomena of higher shear forces but slower cleaning rates in the lower wall section and lower shear forces but faster cleaning rates in the upper wall section imply that the soil is mainly detached by the direct impact of droplets compared with the film.

The results in Figure 4 reveal that pulsed flows are able to remove more deposits from the tank wall than continuous flows at the same effective time, which is defined as the time when flow acts on the tank surface (actual cleaning time subtracted by holding time). There are two causes of the enhanced cleaning performance by pulsed flow: the increased holding time and the improved shear force. The holding time between two bursts can provide additional time for the diffusion of the alkali solution into the soil out layer and therefore improves the reaction. In between two bursts, the out layer of soiling materials swell and become weak, and are therefore more easily detached in the next burst (Kjellberg, 2016). For continuous flow, the impact force and falling film detaches the outer swollen layer constantly. Nevertheless, this process is restricted by the rate of diffusion and swelling, so the mechanical force cannot remove as much soil as it can potentially. However, for the cleaning by pulsed flow, the additional holding time between two pulses enables more soil layers to swell thence removes more soil layers. The improved shear force is due to the unstable falling film when stopping and starting a pulse. It is anticipated that a wavy film forms in the unsteady flow region. Consequently, the local maxima of wall shear stress, even local flow reversal, occurs instantaneously at the front of the unstable free falling film (Tihon et al., 2006, 2003), contributing to the removal of soiling materials by shear force. This effect is similar to pipe or filter cleanings where pulsed flows enhance local wall shear stress and hence improve the cleaning results (Gillham et al., 2000; Weidemann et al., 2014). As discussed above, cleaning by falling film is less significant than by the direct impact from the liquid fan. Therefore, the improved shear force due to pulsed flow can contribute to the cleaning but is not the key factor.

The slopes in Figure 4 indicate the removal rate of uncooked egg yolk deposits by using pulsed flow $\left(P_{l}\right)$. The cleaning dynamics by continuous flow $\left(C_{l}\right)$ were analyzed through discrete observations and are shown in Figure 5. Typical three-phase cleaning dynamics are revealed: the cleaning rate is initially slow due to the swelling of soil, then chunks are removed at constant rate, and finally the removal is limited at the decay phase. This profile is similar to the observations of Gillham et al. (2000) and Goode et al. (2010). The most efficient cleaning occurs at low alkali concentration, high temperature and high flow rate. Among the tested parameters, the alkali concentration and temperature contribute most to the swelling and removal of egg yolk samples, which is also reported by other research groups (Perez-Mohedano et al., 2016). It is interesting to find that the increase in $\mathrm{NaOH}$ concentration from 1 to $5 \mathrm{~kg} / \mathrm{m}^{3}$ reduces the cleaning rate. The preliminary study has proved that the egg yolk soil 
cannot be cleaned only by using water. Therefore, an optimal $\mathrm{NaOH}$ concentration should exist below $5 \mathrm{~kg} / \mathrm{m}^{3}$ to clean egg yolk. Helbig et al. (2018) explained that the removal of egg yolk occurred by diffusive dissolution or cohesive separation in low alkali concentration, in comparison to adhesive detachment in high concentration. Increasing alkali concentration below the optimal value promoted the solubility of lipid due to the hydrolysis of ester bonds and the breakup of hydrogen bonds within the lipoprotein. Whereas, a further rise of sodium hydroxide concentration increased the interactions within the proteins by enhanced hydrogen bonding, hydrophobic interactions and disulfide bridges, leading to worse cleanability. Furthermore, Bird and Fryer (1992, 1991) investigated the cleaning of another protein-based soil (cooked whey protein) and obtained an optimal alkali concentration and temperature as well. They explained that high alkali concentration changed the deposit structure rapidly to form a very thick translucent layer, which was difficult to be removed. Scanning electron microscope (SEM) results revealed that the structure became open with high voidage at the optimal concentration. But the voidage was reduced at even higher alkali concentration. In their study, the optimal parameters for cleaning cooked whey proteins were $50{ }^{\circ} \mathrm{C}$ and $5 \mathrm{~kg} / \mathrm{m}^{3}$ of $\mathrm{NaOH}$ solution. Above the optimal temperature, a chemical reaction occurred and the cleaning rate was reduced.

Even though pulsed flow removes more deposits than continuous flow at the same effective time or at the same alkali consumption, it is necessary to emphasize that pulsed flow may reduce the time efficiency under the investigated flow conditions. Figure 6 rearranges an example from Figure 4 according to the actual cleaning time (effective time plus holding time), inferring that pulsed flow results in less soil removal in the actual timescale. In some industries, saving cleaning time can contribute to production significantly. Hence, an optimization of the pulsed flow parameters is required in order to apply the technique into practices, or the cleaning by pulsed flow is more applicable to the cases where cleaning downtime is not critical. 


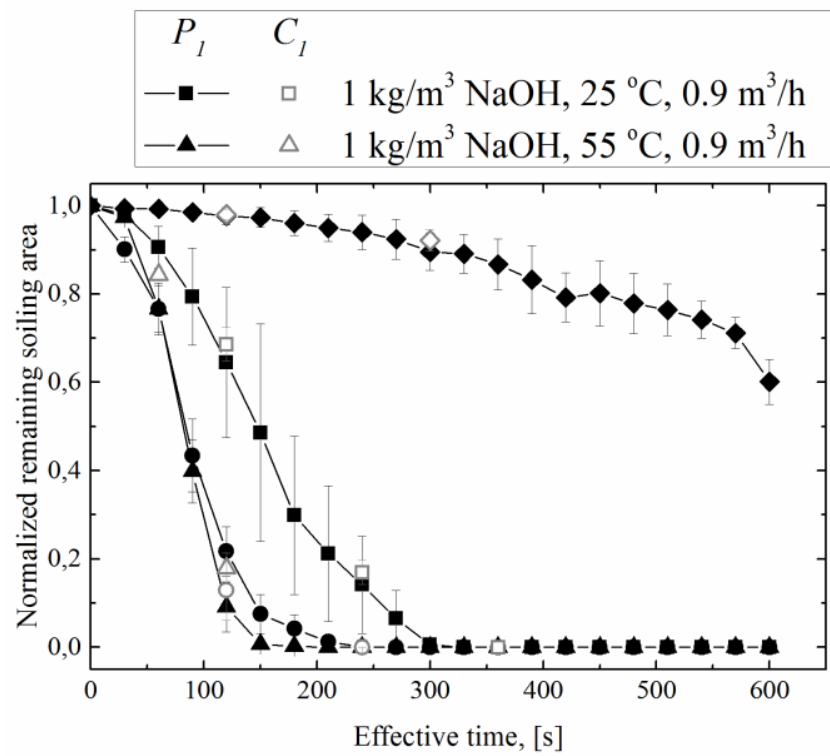

(A) Upper wall

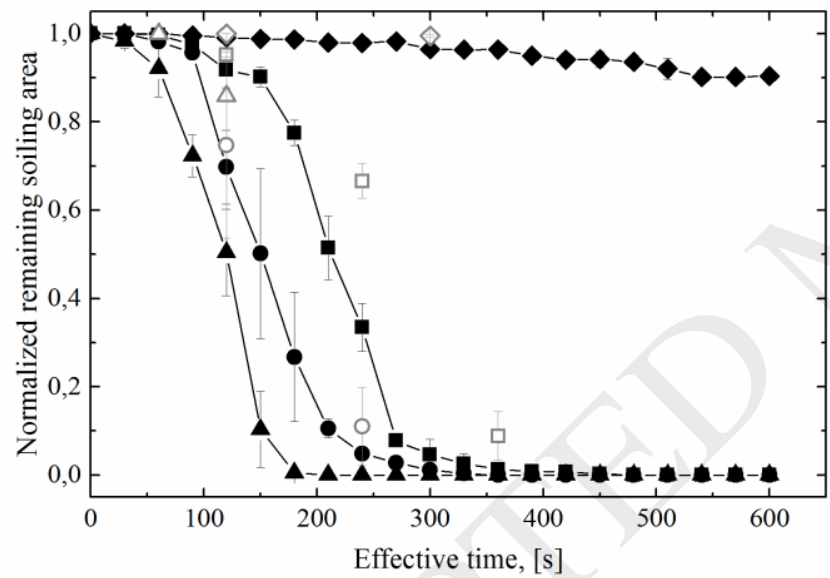

(C) Lower wall
$P_{1} \quad C_{1}$

$-\circ \quad \circ 1 \mathrm{~kg} / \mathrm{m}^{3} \mathrm{NaOH}, 25^{\circ} \mathrm{C}, 1.5 \mathrm{~m}^{3} / \mathrm{h}$

$\longrightarrow \diamond 5 \mathrm{~kg} / \mathrm{m}^{3} \mathrm{NaOH}, 25^{\circ} \mathrm{C}, 0.9 \mathrm{~m}^{3} / \mathrm{h}$

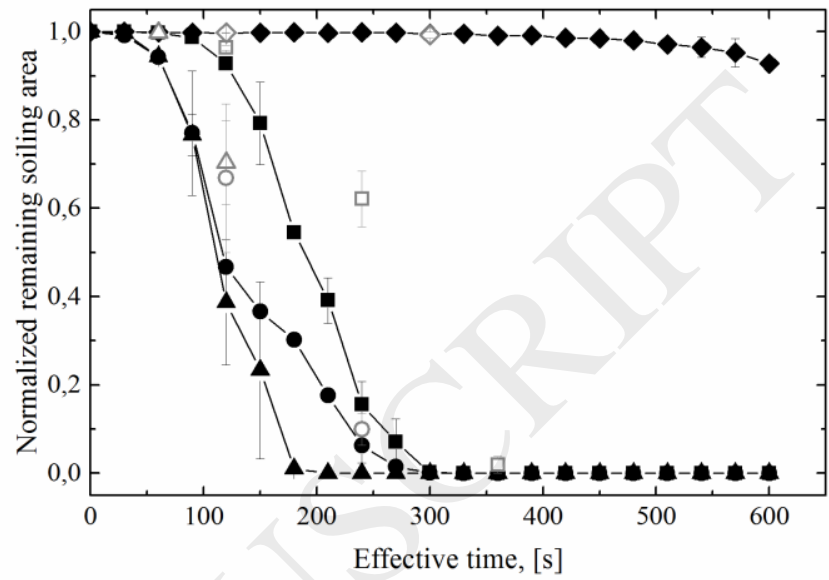

(B) Middle wall

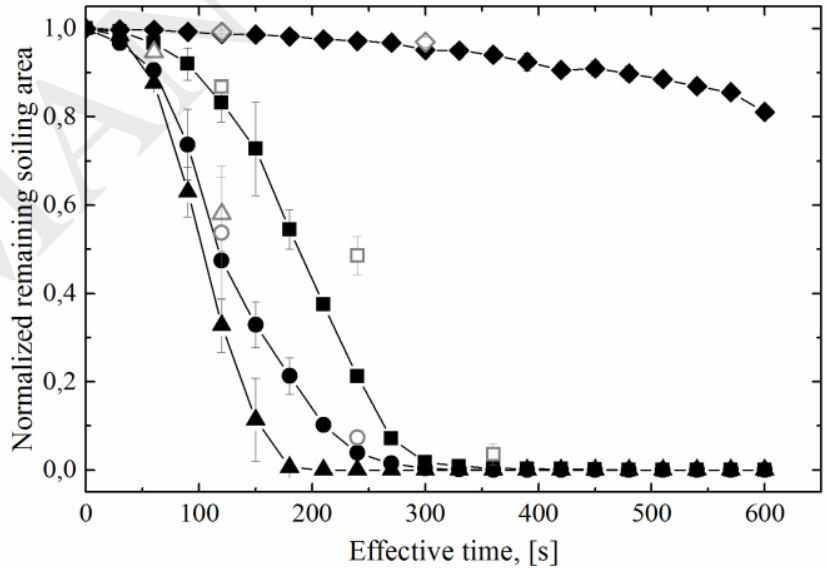

(D) Overall wall

Figure 4 Removal of uncooked soils for different conditions of temperature, flow rate and $\mathrm{NaOH}$ concentration, by using continuous flow without pre-wetting $\left(C_{l}\right)$ or pulsed flow in short period and high frequency $\left(P_{1}\right)$. Only the results of selected runs $1,2,3$ and 5 in Table 1 are displayed. The results for all runs are displayed in Appendix Figure A1: (A) tank upper wall surface, (B) tank middle wall surface, (C) tank lower wall surface, (D) tank overall wall surface. 


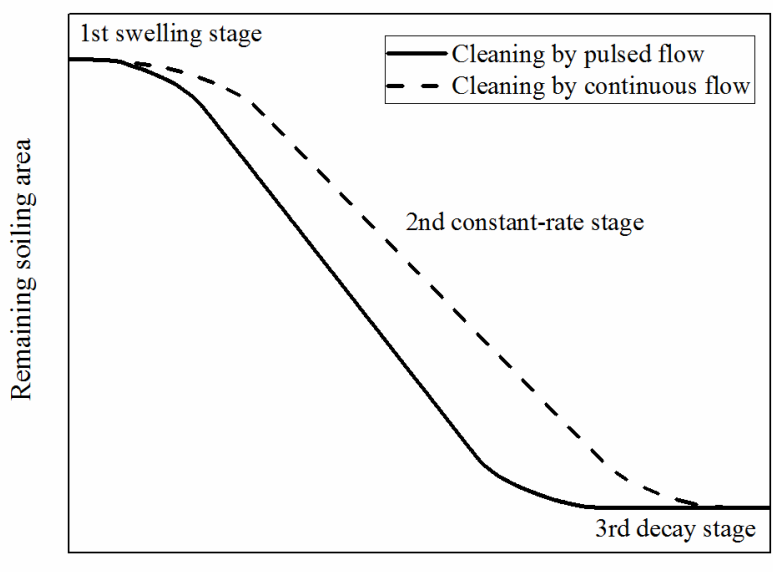

Effective cleaning time

Figure 5 Cleaning dynamics by pulsed or continuous flow

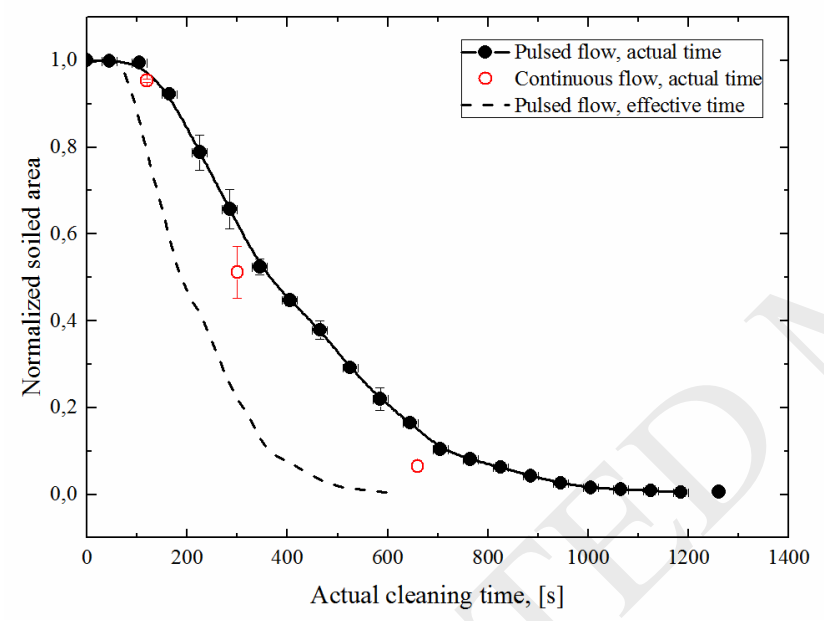

Figure 6 Example of cleaning dynamics $\left(P_{1}\right.$ and $\left.C_{l}\right)$ based on actual cleaning time. The cleaning conditions are: $T=40{ }^{\circ} \mathrm{C}, F R=$ $1.2 \mathrm{~m}^{3} / \mathrm{h}, C=3 \mathrm{~kg} / \mathrm{m}^{3}$. The dash line is the cleaning profile using pulsed flow against effective time, instead of actual cleaning time.

\subsection{Statistical comparison of cleaning by pulsed flow or continuous flow}

To quantitatively compare the effects of different parameters on the cleaning results, an analysis of variance (ANOVA) was used to evaluate the significance of the constructed quadratic model for pulsed flow cleaning $\left(P_{l}\right)$ and continuous flow cleaning $\left(C_{l}\right)$ respectively (Montgomery, 2012). The cleaning results at the same effective cleaning time ( $2 \mathrm{~min}$ ) were extracted from all cleaning runs. The statistical analysis was completed with help of the JMP Software (SAS Institute, US), with results shown in Table 2 and Table 3. The insignificant variables or interaction effects were removed by using stepwise regression control (SRC) to minimize the small-sample-size 
corrected version of the Akaike information criterion (AICc) (JMP 13.0.0 Help, SAS Institute). The remaining variables and interactions are significant at $P<0.05$ (or $P<0.1$ but the $F$ value is very close to the criteria of $P<0.05) . R^{2}$ and Adj- $R^{2}$ explain the goodness of the model to fit the experimental data, and Pred- $R^{2}$ indicates how well the model is to fit new data (Montgomery, 2012). The general range of $R^{2}$ values was between 0.843 and 0.983, indicating that the models are adequate (Palabiyik et al., 2015), i.e. the models describe the data satisfactorily. The coefficients for the second-order regression model are listed in Table 4.

The results in Table 2 and Table 3 show the effects of the investigated parameters on the cleaning behavior, that:

- For both cleaning approaches (continuous $C_{l}$ and pulsed $P_{l}$ ), the most important parameter of the cleaning process is the alkali concentration $\left(X_{3}\right)$. Furthermore, the main effects of temperature $\left(X_{1}\right)$ and flow rate $\left(X_{2}\right)$ as well as the interactions between temperature and alkali concentration $\left(X_{1} X_{3}\right)$ and between flow rate and alkali concentration $\left(X_{2} X_{3}\right)$ are significant as well. The interaction between temperature and flow rate $\left(X_{1} X_{2}\right)$ can, however, be eliminated.

- For pulsed flow cleaning, the effect of temperature and its interaction with alkali concentration are greater than the effects of flow rate and its interaction with alkali concentration. In contrast, the opposite is true for continuous flow cleaning.

- The quadratic curvature in the response model, implied by the lack-of-fit statistic, is insignificant or less significant compared with the other main factors or interactions. However, the current experimental design with only one replicated center point cannot identify which of the three variables exhibit curvature. An alternative design is to augment the $2^{3}$ design with more axial runs, called a central composite design (Montgomery, 2012; Palabiyik et al., 2015). Nonetheless, this study keeps the proposed design and model, because the curvature effect is less significant than the others in the studied ranges of conditions.

Table 2 Analysis for the cleaning of uncooked soil by using pulsed flow $\left(P_{l}\right)$ at 2 min of effective time

\begin{tabular}{|c|c|c|c|c|c|c|c|c|}
\hline \multirow{2}{*}{ Source of Variance } & \multicolumn{2}{|c|}{ Upper wall } & \multicolumn{2}{|c|}{ Middle wall } & \multicolumn{2}{|c|}{ Lower wall } & \multicolumn{2}{|c|}{ Overall wall } \\
\hline & $\mathrm{DF}^{\mathrm{e}}$ & $F$ & $\mathrm{DF}^{\mathrm{e}}$ & $F$ & $\overline{D^{e}}$ & $F$ & $\mathrm{DF}^{\mathrm{e}}$ & $F$ \\
\hline Model & 5 & $44.62^{\mathrm{a}}$ & 5 & $52.19^{\mathrm{a}}$ & 5 & $29.39^{\mathrm{a}}$ & 5 & $136.18^{\mathrm{a}}$ \\
\hline$X_{I}$ & 1 & $13.40^{\mathrm{a}}$ & 1 & $21.72^{\mathrm{a}}$ & 1 & $28.15^{\mathrm{a}}$ & 1 & $81.86^{\mathrm{a}}$ \\
\hline$X_{2}$ & 1 & $7.65^{b}$ & 1 & $26.32^{\mathrm{a}}$ & 1 & $11.19^{\mathrm{a}}$ & 1 & $44.21^{\mathrm{a}}$ \\
\hline$X_{3}$ & 1 & $183.85^{\mathrm{a}}$ & 1 & $148.92^{\mathrm{a}}$ & 1 & $74.35^{\mathrm{a}}$ & 1 & $442.82^{\mathrm{a}}$ \\
\hline$X_{1} X_{2}$ & $\mathrm{SRC}^{\mathrm{d}}$ & & $\mathrm{SRC}^{\mathrm{d}}$ & & $\mathrm{SRC}^{\mathrm{d}}$ & & $\mathrm{SRC}^{\mathrm{d}}$ & \\
\hline$X_{1} X_{3}$ & 1 & $13.49^{\mathrm{a}}$ & 1 & $33.79^{\mathrm{a}}$ & 1 & $24.18^{\mathrm{a}}$ & 1 & $79.30^{\mathrm{a}}$ \\
\hline
\end{tabular}




\begin{tabular}{ccccccccc}
\hline$X_{2} X_{3}$ & 1 & $4.72^{\mathrm{c}}$ & 1 & $20.21^{\mathrm{a}}$ & 1 & $9.06^{\mathrm{b}}$ & 1 & $32.69^{\mathrm{a}}$ \\
Residual & 12 & & 12 & & 12 & & 12 & 3.34 \\
Lack of Fit & 3 & 2.30 & 3 & 0.83 & 3 & $6.71^{\mathrm{b}}$ & 3 & 9 \\
Pure Error & 9 & & 9 & & 9 & & 17 \\
Total Model & 17 & & 17 & 17 & 0.924 & 0.983 \\
$R^{2}$ & & 0.949 & 0.956 & 0.938 & 0.893 & 0.975 \\
Adj- $R^{2}$ & 0.928 & 0.917 & 0.849 & 0.968
\end{tabular}

${ }^{\mathrm{a}} P \leq 0.01$

${ }^{\mathrm{b}} P \leq 0.05$

${ }^{\mathrm{c}} P \leq 0.1$

${ }^{\mathrm{d}}$ SRC: Removed by "stepwise regression control" model

${ }^{\mathrm{e}}$ DF: Degree of freedom

Table 3 Analysis for the cleaning of uncooked soil by using continuous flow $\left(C_{1}\right)$ at 2 min of effective time

\begin{tabular}{|c|c|c|c|c|c|c|c|c|}
\hline \multirow{2}{*}{ Source of Variance } & \multicolumn{2}{|c|}{ Upper wall } & \multicolumn{2}{|c|}{ Middle wall } & \multicolumn{2}{|c|}{ Lower wall } & \multicolumn{2}{|c|}{ Overall wall } \\
\hline & $\mathrm{DF}^{\mathrm{e}}$ & $F$ & $\mathrm{DF}^{\mathrm{e}}$ & $F$ & $\mathrm{DF}^{\mathrm{e}}$ & $F$ & $\mathrm{DF}^{\mathrm{e}}$ & $F$ \\
\hline Model & 5 & $26.08^{a}$ & 5 & $16.45^{\mathrm{a}}$ & 5 & $12.90^{\mathrm{a}}$ & 5 & $23.09^{\mathrm{a}}$ \\
\hline$X_{1}$ & 1 & $4.84^{b}$ & 1 & $10.32^{\mathrm{a}}$ & 1 & $7.71^{\mathrm{b}}$ & 1 & $10.30^{\mathrm{a}}$ \\
\hline$X_{2}$ & 1 & $8.15^{\mathrm{b}}$ & 1 & $12.91^{\mathrm{a}}$ & 1 & $15.28^{\mathrm{a}}$ & 1 & $14.33^{\mathrm{a}}$ \\
\hline$X_{3}$ & 1 & $105.70^{\mathrm{a}}$ & 1 & $36.24^{\mathrm{a}}$ & 1 & $26.19^{a}$ & 1 & $69.77^{\mathrm{a}}$ \\
\hline$X_{1} X_{2}$ & $\mathrm{SRC}^{\mathrm{d}}$ & & $\mathrm{SRC}^{\mathrm{d}}$ & & $\mathrm{SRC}^{\mathrm{d}}$ & & $\mathrm{SRC}^{\mathrm{d}}$ & \\
\hline$X_{1} X_{3}$ & 1 & $5.69^{\mathrm{b}}$ & 1 & $10.84^{\mathrm{a}}$ & 1 & $4.68^{c}$ & 1 & $9.79^{\mathrm{a}}$ \\
\hline$X_{2} X_{3}$ & 1 & $6.02^{b}$ & 1 & $11.95^{\mathrm{a}}$ & 1 & $10.62^{\mathrm{a}}$ & 1 & $11.26^{\mathrm{a}}$ \\
\hline Residual & 12 & & 12 & & 12 & & 12 & \\
\hline Lack of Fit & 3 & $37.03^{\mathrm{a}}$ & 3 & $4.04^{\mathrm{b}}$ & 3 & $5.57^{\mathrm{b}}$ & 3 & 3.51 \\
\hline Pure Error & 9 & & 9 & & 9 & & 9 & \\
\hline Total Model & 17 & & 17 & & 17 & & 17 & \\
\hline$R^{2}$ & \multicolumn{2}{|c|}{0.916} & \multicolumn{2}{|c|}{0.873} & \multicolumn{2}{|c|}{0.843} & \multicolumn{2}{|c|}{0.906} \\
\hline $\operatorname{Adj}-R^{2}$ & \multicolumn{2}{|c|}{0.881} & \multicolumn{2}{|c|}{0.820} & \multicolumn{2}{|c|}{0.778} & \multicolumn{2}{|c|}{0.867} \\
\hline
\end{tabular}




\begin{tabular}{|c|c|c|c|c|c|c|c|c|}
\hline Pred- $R^{2}$ & & 0.839 & & 0.6 & & & 592 & \\
\hline${ }^{\mathrm{a}} P \leq 0.01$ & & & & & & & & \\
\hline${ }^{\mathrm{b}} P \leq 0.05$ & & & & & & & & \\
\hline${ }^{\mathrm{c}} P \leq 0.1$ & & & & & & & & \\
\hline${ }^{\mathrm{d}}$ SRC: Removed by & "stepwis & regressi & on control & $"$ model & & & & \\
\hline${ }^{\mathrm{e}} \mathrm{DF}$ : Degree of fre & dom & & & & & & & \\
\hline Table 4 Param & ents of th & secon & or reorecsic & odel fo & alood & & & \\
\hline Donom & & Pulsed $\mathrm{f}$ & low $\left(P_{1}\right)$ & & & ontinuor & s flow $(C$ & \\
\hline I alanters & Upper & Middle & Lower & Overall & Upper & Middle & Lower & Overall \\
\hline$\beta_{0}$ & 1.336 & 2.206 & 2.094 & 1.881 & 1.543 & 2.360 & 1.955 & 1.946 \\
\hline$\beta_{1},\left[{ }^{\circ} \mathrm{C}^{-1}\right]$ & -0.016 & -0.021 & -0.021 & -0.020 & -0.013 & -0.017 & -0.010 & -0.014 \\
\hline$\beta_{2},\left[\mathrm{~m}^{-3} \mathrm{~h}\right]$ & -0.528 & -0.869 & -0.653 & -0.670 & -0.756 & -0.941 & -0.731 & -0.783 \\
\hline$\beta_{3},\left[\mathrm{~kg}^{-1} \mathrm{~m}^{3}\right]$ & -0.065 & -0.234 & -0.206 & -0.169 & -0.102 & -0.267 & -0.171 & -0.179 \\
\hline$\beta_{12},\left[{ }^{\circ} \mathrm{C}^{-1} \mathrm{~m}^{-3} \mathrm{~h}\right]$ & 0 & 0 & 0 & 0 & 0 & 0 & 0 & 0 \\
\hline$\beta_{13},\left[{ }^{\circ} \mathrm{C}^{-1} \mathrm{~kg}^{-1} \mathrm{~m}^{3}\right]$ & 0.0032 & 0.0043 & 0.0041 & 0.0039 & 0.0028 & 0.0035 & 0.0018 & 0.0028 \\
\hline$\beta_{23},\left[\mathrm{~h} \mathrm{~kg}^{-1}\right]$ & 0.0951 & 0.165 & 0.125 & 0.126 & 0.142 & 0.185 & 0.135 & 0.149 \\
\hline
\end{tabular}

The improvement of cleaning by using pulsed flow can be calculated as the difference of the predicted normalized remaining soiling area by pulsed flow or by continuous flow. Figure 7 plots this difference by fitting the secondorder regression model (equation 2) using the coefficients in Table 4. It is found that:

- The effects of pulsed flow on cleaning are generally positive in the studied range of parameters, meaning pulsed flow is able to remove more deposits from the tank wall compared with continuous flow.

- The difference between pulsed flow and continuous flow is more significant at high temperature and at low alkali concentration. The change of flow rate does not make a large difference between two cleaning methods. This is because temperature and alkali concentration are key factors contributing to reactions, which is in line with the idea of pulsed flow cleaning enabling longer reaction time. Higher flow rate leads to greater mechanical impact, which, however, is not the limiting factor in this study because the flow rate in the investigated range is high enough to detach the swollen soils. 
- The difference between the two cleaning approaches is less substantial at the upper wall section than at the lower wall section. The distance from the rotary spray head to the tank surface increases from the tank top to the bottom. Hence, the mechanical force exhibited on the wall declines from the upper section to the lower section. As discussed above, the improvement of cleaning by pulsed flow is less affected by this impact. Therefore, the enhancement of cleaning by pulsed flow becomes less apparent at the upper wall section.

- For the lower wall section or the overall wall, the greatest improvement by using pulsed flow occurs at high temperature and low flow rate, or low alkali concentration and high flow rate. At low temperature and high alkali concentration, the contribution of the flow rate is small. 


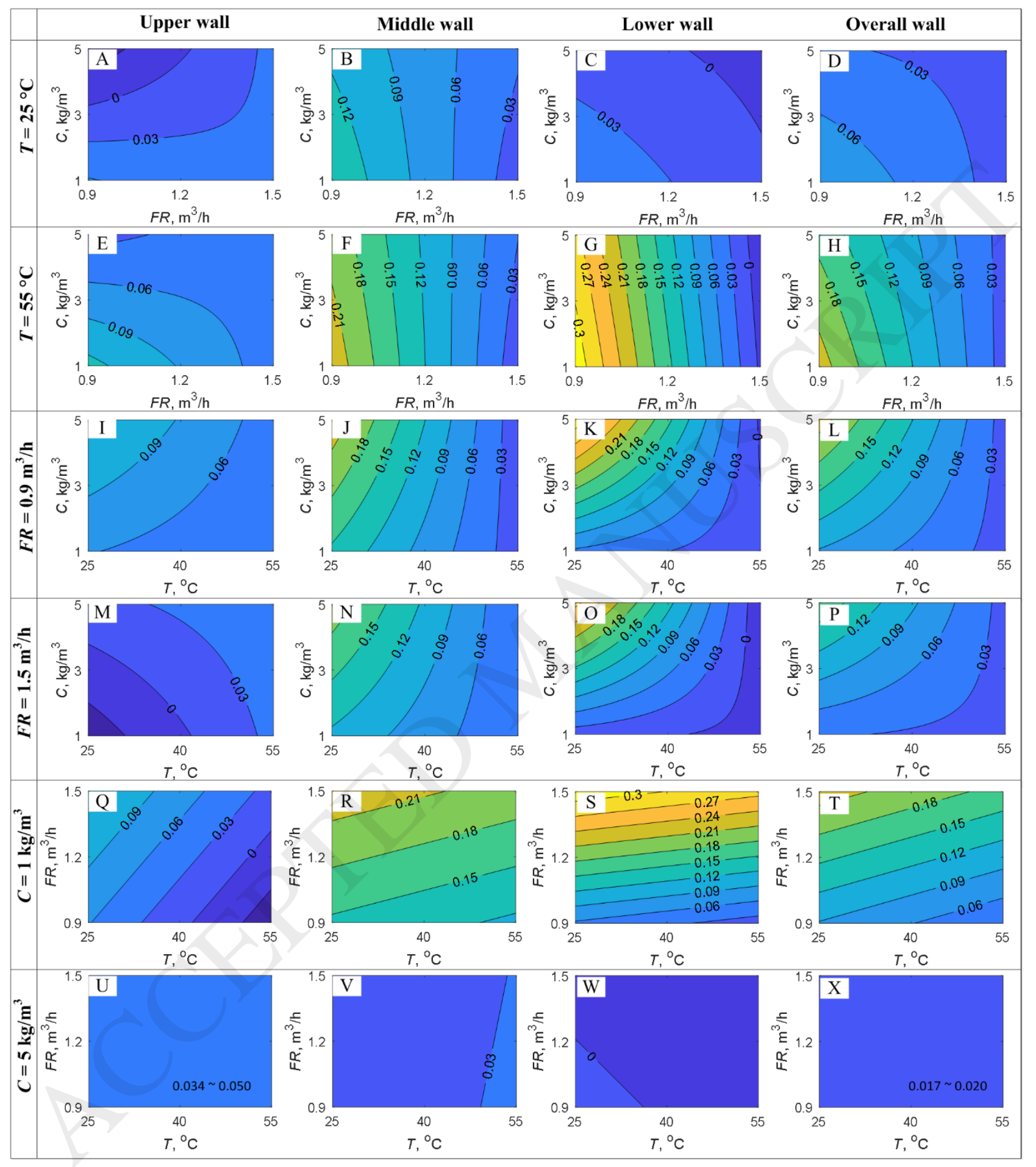

Figure 7 The difference of normalized remaining soiling area of uncooked soil between pulsed flow cleaning $\left(P_{l}\right)$ and continuous flow cleaning $\left(C_{l}\right)$. The results are based on the effective cleaning of $2 \mathrm{~min}$. A positive value indicates that the effect of pulsed flow is positive. Yellow color denotes significant difference; dark blue color denotes insignificant difference. 


\subsection{Cleaning of uncooked soils with different pulsed and continuous approaches}

Figure 8 shows the cleaning of uncooked soil with different pulsed and continuous approaches. After final rinse, the improvement of cleaning using pulsed flows is observed but not obvious in the upper and middle wall sections when comparing with continuous flows. This is because only the pictures after final rinse were taken during the cleaning by continuous flow, when most soil deposits have been removed. It has been indicated in Figure 5 that the improvement by pulsed flow is the most significant at the stage when chunks of deposits are removed at a constant rate (normally ca. 150 - $500 \mathrm{~s}$ effective time for the upper and middle wall sections). Therefore, it is a logical deduction that a more clear difference between the pulsed and continuous approaches can be observed at some latent time points during alkali circulation. In Figure 8C, pulsed flow can remove ca. 15\% more soils than continuous flow at the lower wall section. It confirms the hypothesis that a clear difference occurs before the cleaning approaches to the end, as the cleaning of the lower wall section still lies in the constant-rate stage (illustrated in Figure 5) after final rinse.

Pulsed flow with lower frequency $\left(P_{2}\right)$ is less effective than that with higher frequency $\left(P_{1}\right)$ at the upper wall section, middle wall section and the overall surface. The repeated bursts of liquid contribute to removing the swollen soil layers instantly by mechanical force, exposing the hard layers to the fresh liquid to react in the next burst. However, the low impact force at the lower wall section restricts the removal of the outer layer of soil (Jensen, 2007) thereby the influence of pulse frequency is not significant with respect to the experimental deviations.

Gordon et al., (2012) suggested that pre-wetting protein soils before cleaning is able to swell the soil layer initially and ease the following removal. Lerch et al., (2013) compared the removal of soluble ingredient riboflavin by falling films with or without pre-wetting, and found that pre-wetting of dried soil achieved an enhanced cleaning. Nonetheless, through comparing the cleaning results between continuous flow $\left(C_{1}\right)$ and pre-wetting $\left(C_{2}\right)$ as shown in Figure 8, the difference of normalized remaining soiling area to the overall wall is less than $2 \%$. Therefore, the contribution of pre-wetting in this study is not apparent, because the water film is unable to attach to the vertical tank wall consistently as soaking, that is, by submerging soil layers in liquid phase. As a result, pre-swelling is minor to augment cleaning.

The remaining soiling areas decrease at the effective cleaning time of $600-660 \mathrm{~s}$ in all wall sections, indicating that the final water rinse favors the removal of deposits as well. Some alkali solution remains in the CIP forward pipe at the initial stage of the final rinse, whereas it is only a short period during the one-minute action. The results in this study imply that mechanical forces rather than chemical reaction dominates soil removal towards the end of the cleaning operation. 


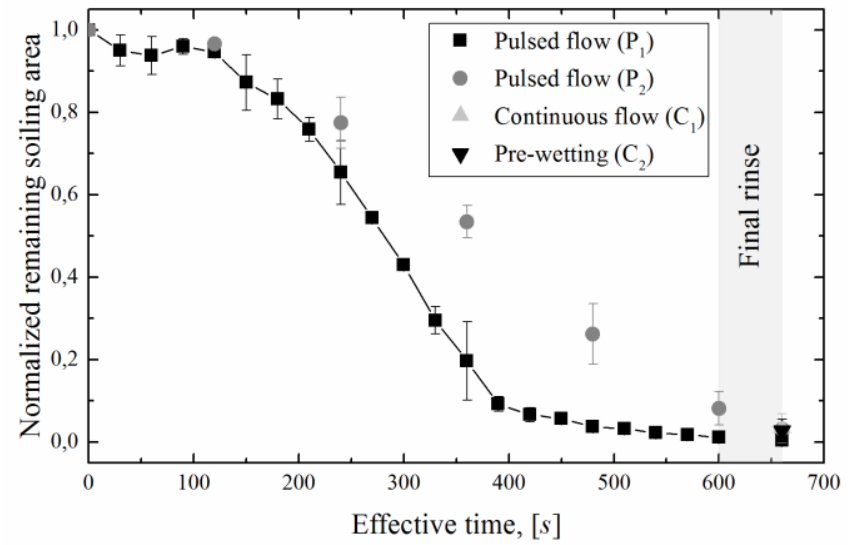

(A) Upper wall

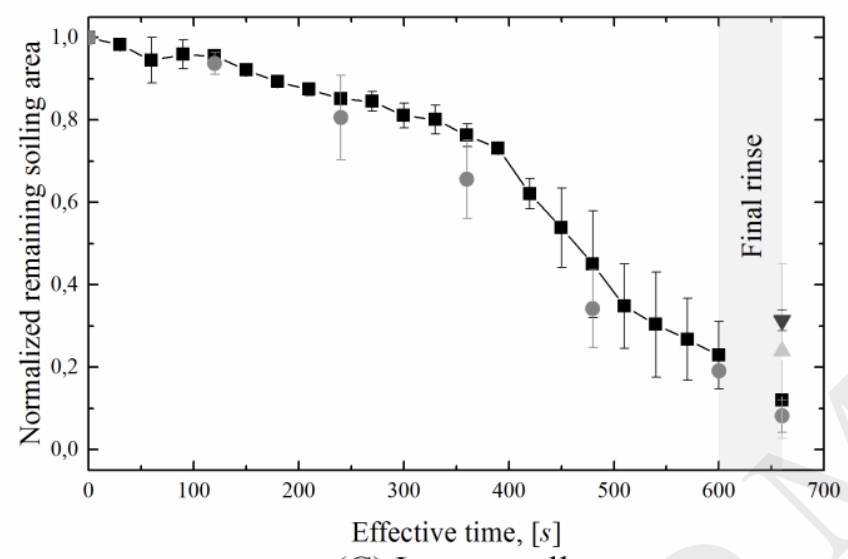

(C) Lower wall

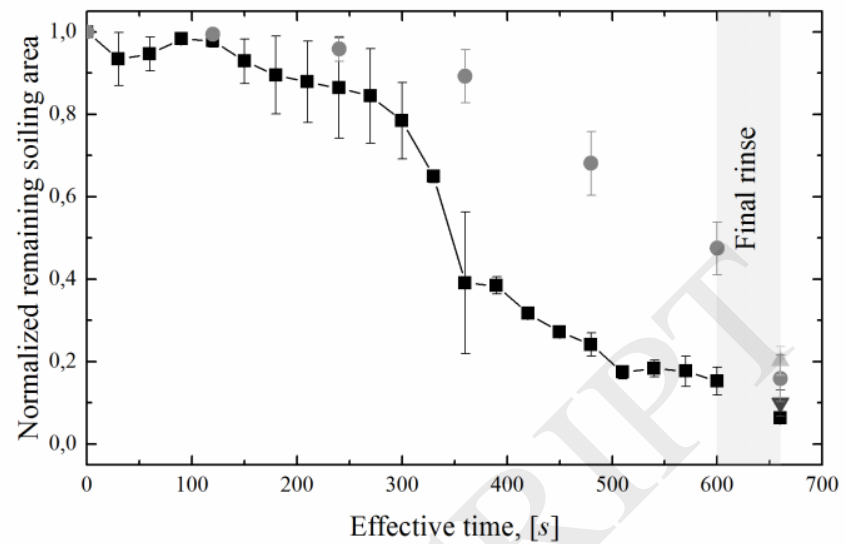

(B) Middle wall

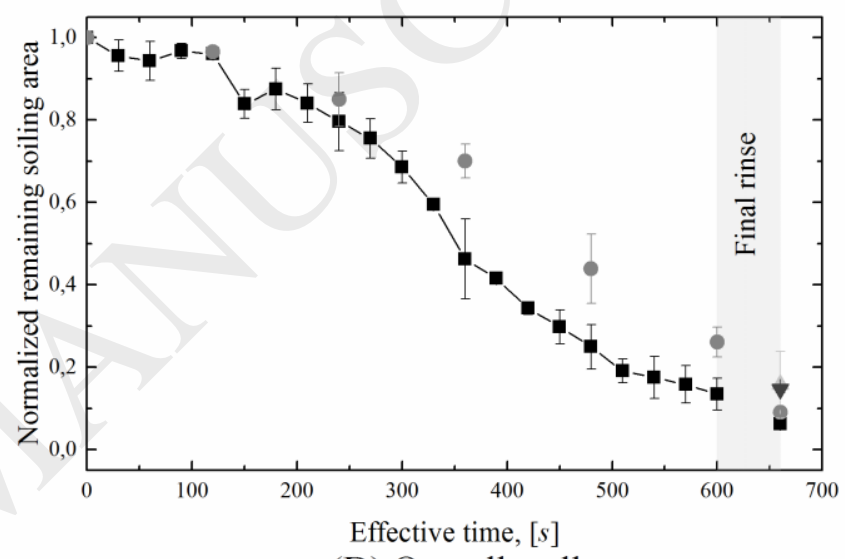

(D) Overall wall

Figure 8 Comparison of cleaning uncooked soils by different continuous and pulsed approaches: (A) tank upper wall surface, (B) tank middle wall surface, (C) tank lower wall surface, (D) tank overall wall surface. The cleaning conditions are: $T=55^{\circ} \mathrm{C}, F R=$ $1.5 \mathrm{~m}^{3} / \mathrm{h}, C=5 \mathrm{~kg} / \mathrm{m}^{3}$.

\subsection{Optimization of cleaning}

Optimizing a CIP procedure aims not only to minimize the consumption of resources but to maximize the cleanliness while reducing costs. Figure 9 displays the cleaning costs per degree of cleaning at the optimal operational conditions. For pulsed flow cleaning, the most cost-efficient operation occurs at high temperature, low flow rate and low alkali concentration. On the contrary, the optimal conditions for continuous flow cleaning are high temperature, high flow rate and low alkali concentration. With both approaches, the chemical consumption is the main contribution to the overall cost whereas the cost of electricity is negligible, which is in accordance with previous findings obtained when mapping CIP procedures in a brewery (Yang et al., 2018).

As indicated in Figure 9, under the optimal cleaning conditions, cleaning uncooked soil by pulsed flow reduces $25 \%$ of the cost to achieve per degree of cleanliness. However, when performing cleaning under their most 
economical conditions, only $65 \%$ of soils is removed by pulsed flow after 2 minutes in comparison with $80 \%$ of removal by continuous flow, for the sake of higher flow rate when cleaning by continuous flow. Table 5 compares the total cleaning costs to remove $80 \%$ soil materials $(y=0.20)$ from the surface by continuous flow or pulsed flow, where the flow conditions of pulsed flow are determined from the optimal conditions in Figure 9. The cost saving by pulsed flow is $21-31 \%$ compared to the cleaning by continuous flow. However, an increase in downtime should be considered when implementing burst cleaning in practice, as indicated in Figure 6. It can still be concluded that tank cleaning by using pulsed flow makes the per unit consumption of cleaning detergent more valuable.

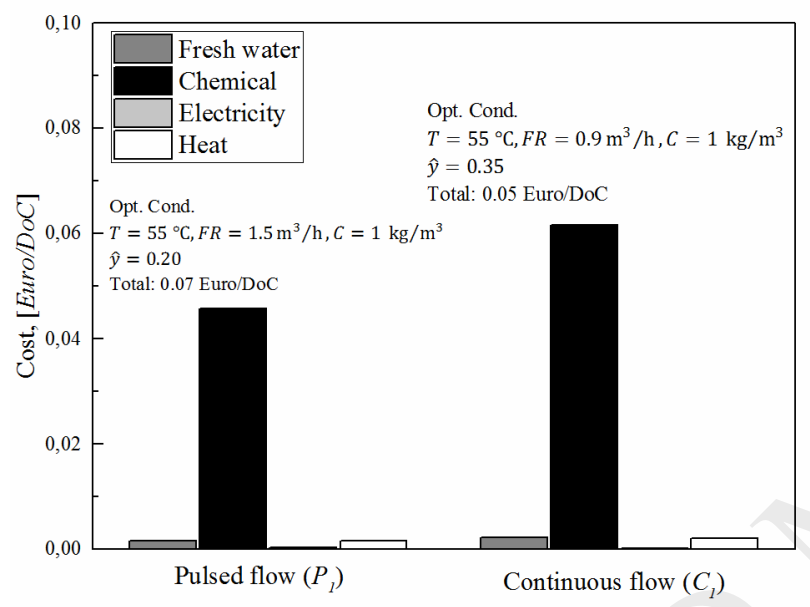

Figure 9 Comparison of the cleaning costs of uncooked soil by pulsed flow $\left(P_{l}\right)$ and continuous flow $\left(C_{l}\right)$ under optimal conditions. The degree of cleaning is defined at the effective cleaning time of 2 min.

Table 5 Comparison of cleaning to achieve the same cleanliness $(y=0.20)$ by using pulsed flow $\left(P_{l}\right)$ and continuous flow $\left(C_{l}\right)$.

\begin{tabular}{cccc}
\hline Parameters & Continuous flow $\left(C_{l}\right)$ & \multicolumn{2}{c}{ Pulsed flow $\left(P_{l}\right)$} \\
\hline$T,\left[{ }^{\circ} \mathrm{C}\right]$ & 55 & 55 & 55 \\
$F R,\left[\mathrm{~m}^{3} / \mathrm{h}\right]$ & 1.5 & 1.5 & 0.9 \\
$C,\left[\mathrm{~kg} / \mathrm{m}^{3}\right]$ & 1 & 1 & 1 \\
Effective cleaning time $^{\mathrm{a}},[\mathrm{s}]$ & 120 & 95 & 138 \\
Actual cleaning time $^{\mathrm{a}},[\mathrm{s}]$ & 120 & 185 & 258 \\
${\text { Total cost, }\left[10^{-2} \text { Euro/DoC }\right]}_{\text {Cost saving }}$ & 6.6 & 5.2 & 4.6 \\
& - & $21 \%$ & $31 \%$
\end{tabular}

$\bar{a}$ Effective cleaning time denotes the circulation time of alkali solution. Actual cleaning time is the sum of effective cleaning time and holding time. 


\subsection{Cleaning of cooked soils with different approaches}

Figure 10 shows the cleaning results of cooked soils by different continuous and pulsed approaches. Larger soiling areas are obtained in all observations when comparing with the cleaning of uncooked soils at the same flow conditions (Figure 8). The difference is caused by the nature of deposits, which can strongly affect the cleaning behavior. Heating protein soil over its denaturation temperature makes the material harder to remove (Gordon et al., 2012). Some results of cleaning cooked soil are consistent with the results of cleaning uncooked soil: pulsed flow improves cleaning compared with continuous flow; higher pulse frequency favors the removal of deposits at the upper wall section than lower pulse frequency; the final rinse with water can detach the swollen soil when the cleaning tends to finish.

However, the influence of pulsed flows becomes more noticeable during the cleaning of cooked soil compared with the cleaning of uncooked soil. Taking the continuous flow cleaning $C_{l}$ as contrast, the cleanings performed by pulsed flow with low frequency $\left(P_{2}\right)$ and pulsed flow with high frequency $\left(P_{l}\right)$ can respectively improve the removal of deposits by $33.0 \%$ and $51.1 \%$ of the overall surface. However, the negative improvement by prewetting to the middle wall section can be associated with experimental deviations, as displayed in Figure $10 \mathrm{~B}$. 


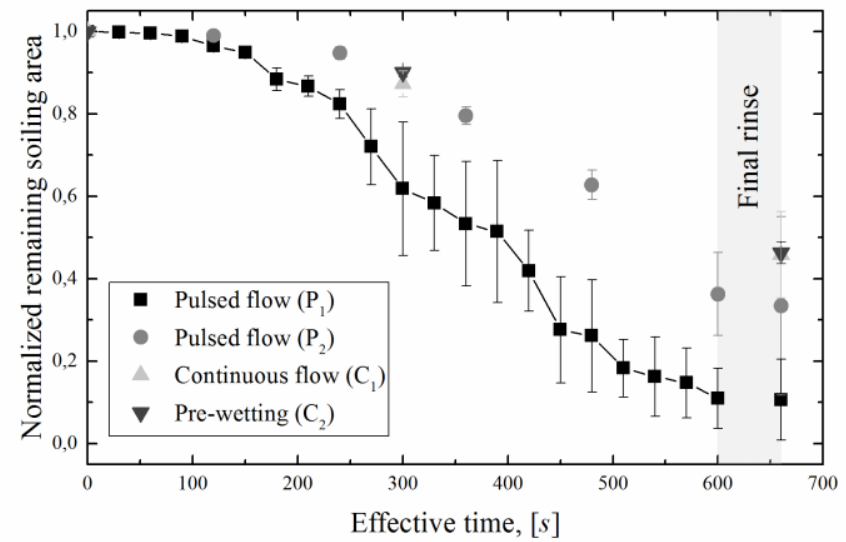

(A) Upper wall

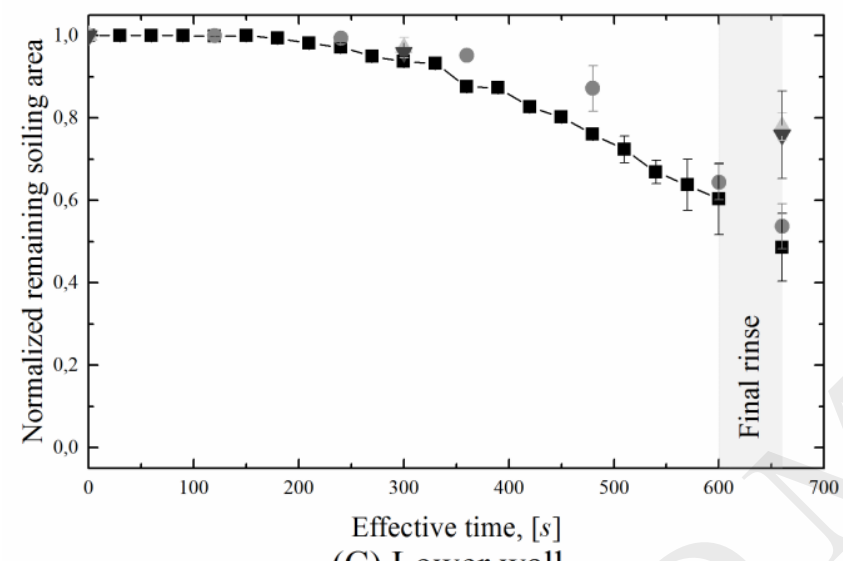

(C) Lower wall

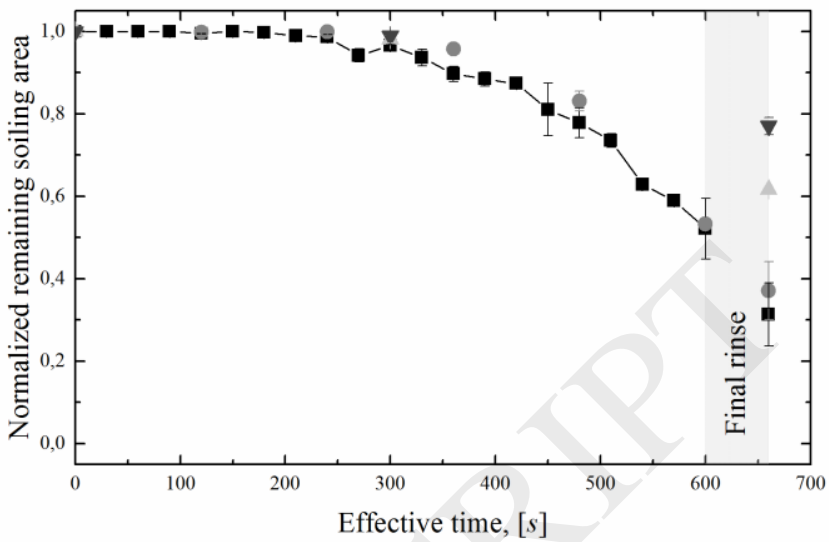

(B) Middle wall

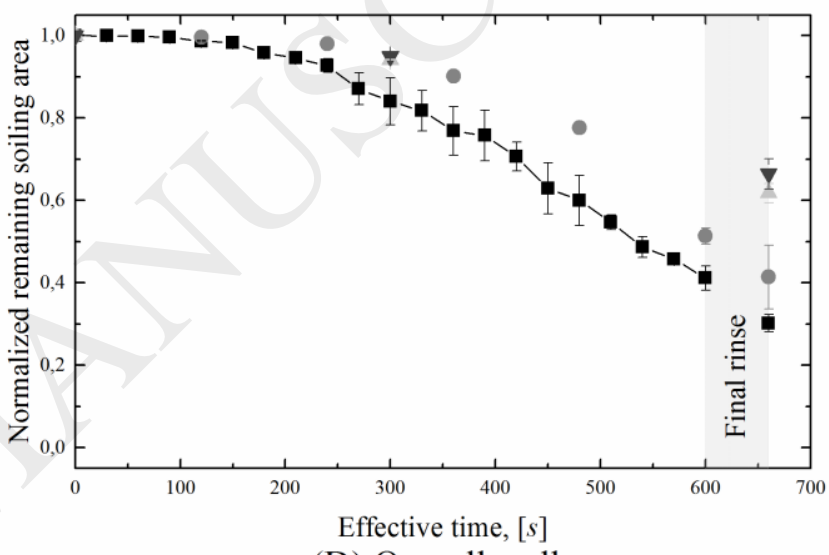

(D) Overall wall

Figure 10 Comparison of cleaning cooked soils by different continuous and pulsed approaches: (A) tank upper wall surface, (B) tank middle wall surface, (C) tank lower wall surface, (D) tank overall wall surface. The cleaning conditions are: $T=55^{\circ} \mathrm{C}, F R=1.5 \mathrm{~m}^{3} / h, C=$ $5 \mathrm{~kg} / \mathrm{m}^{3}$.

\subsection{Cleaning in a large scale tank}

Scale-up studies were performed in a $19 \mathrm{~m}^{3}$ tank to verify the above-mentioned conclusions. The setup has been previously described by other researchers (Feldung Damkjær et al., 2017; Stenby et al., 2012). Briefly speaking, the diameter of the test tank is $2.8 \mathrm{~m}$ (Figure 11A). A mobile CIP unit supplies liquid at pre-defined temperature and feed pressure. Egg yolk soils were spread on a separated bent plate using the same metal rod as in the pilotscale experiment, forming soil layers of $1 \mathrm{~mm}$ thickness. A rectangle region of $55 \times 24 \mathrm{~cm}^{2}$ was marked for investigation, which was slightly smaller than the actual soiling area (Figure 11C). After three-day drying at room temperature, the plate was fixed on the tank wall and cleaned with help of a single axis rotary spray head (SaniMagnum $360^{\circ}$, Alfa Laval, Denmark), as illustrated in Figure 11B. The cleaning conditions were: $\mathrm{NaOH}$ concentration 1 or $5 \mathrm{~kg} / \mathrm{m}^{3}, 25 \pm 3{ }^{\circ} \mathrm{C}, 2$ bar (corresponding to the flow rate of $11.4 \mathrm{~m}^{3} / \mathrm{h}$ ). The cleaning methods included continuous flow and pulsed flow (with a period of $60 \mathrm{~s}$ or $2 \mathrm{~min}$ ). The effective cleaning time was 5 min. 
Most experiments were carried out once. One repetition of the burst cleaning at low $\mathrm{NaOH}$ concentration and low frequency proved the reproducibility of experiments (5\% difference). Therefore, the experimental error was assumed to be small, assumed to be smaller than $10 \%$.

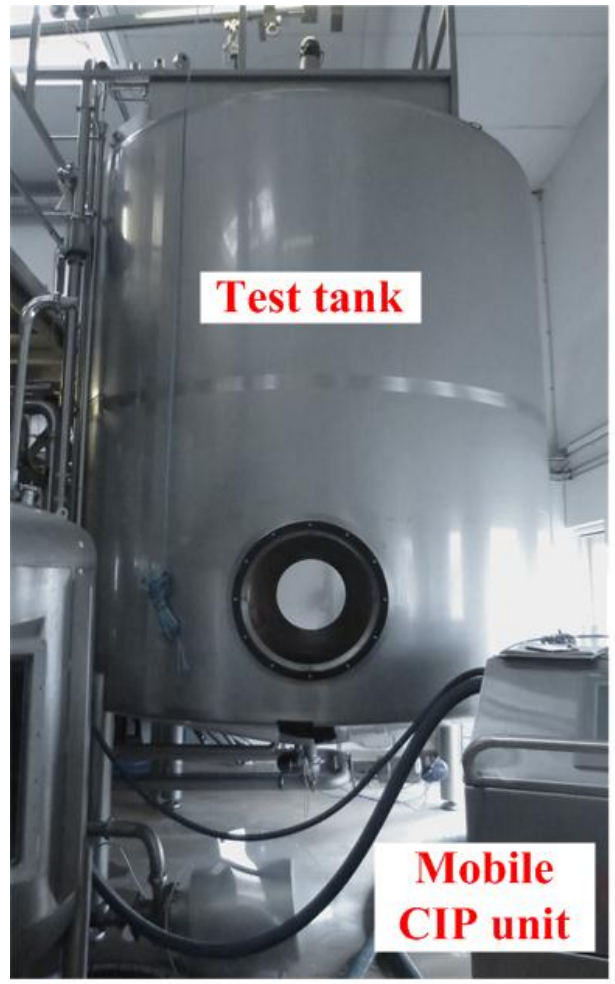

(A)

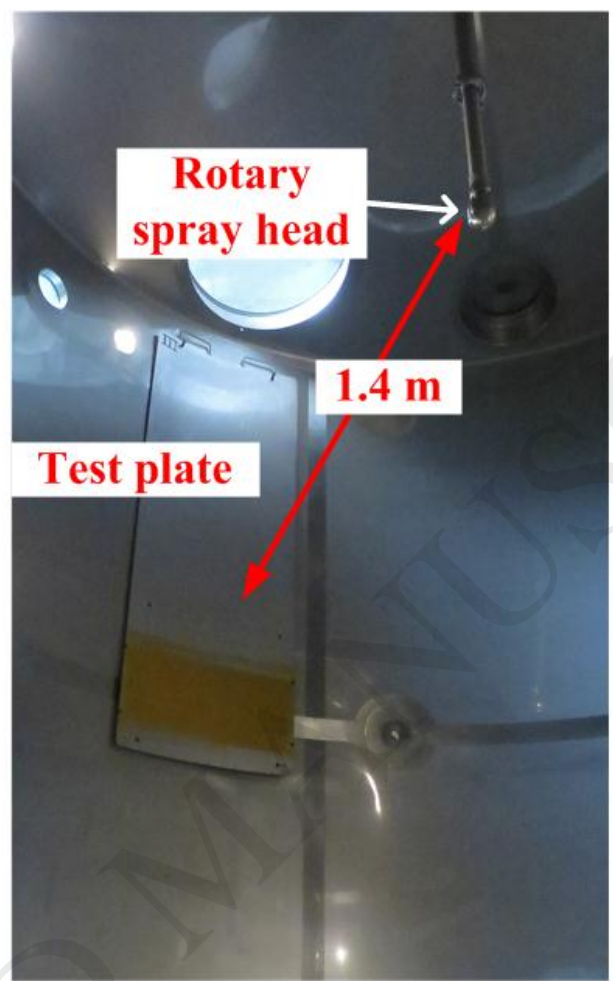

(B)

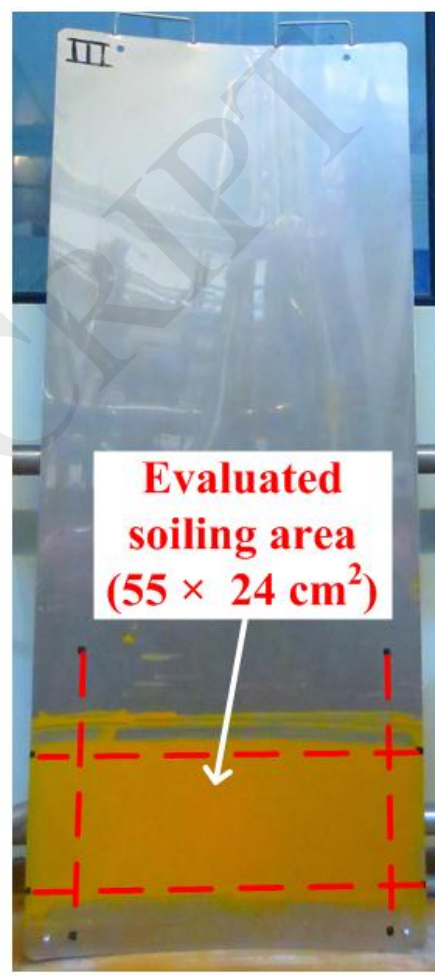

(C)

Figure 11 Photographs of the apparatus used for scale-up experiments: (A) the test tank, (B) the test plate and rotary spray head and (C) the investigated soiling area.

Figure 12 shows the photographs of the test plates using different methods. By comparing Figure 12B-D, the pulsed flow with short period of $60 \mathrm{~s}$ removes all soils, leading to the best cleaning results at low $\mathrm{NaOH}$ concentration $\left(1 \mathrm{~kg} / \mathrm{m}^{3}\right)$. This result is consistent with the findings in pilot-scale tests. However, it is interesting to observe that the pulsed flow with the period of $2 \mathrm{~min}$ results in less cleanliness than the continuous flow, which can be attributed to reasonable experimental errors. As expected from previous findings, increasing the $\mathrm{NaOH}$ concentration to $5 \mathrm{~kg} / \mathrm{m}^{3}$ (Figure 12E\&F) reduces the cleaning efficiency. Therefore, the conclusions drawn from pilot-scale experiments also apply to scale-up tests. That is, the pulsed flow with a short period and high frequency is the most efficient to remove egg yolk soils from the tank surfaces; high alkali concentration (up to $5 \mathrm{~kg} / \mathrm{m}^{3}$ ) contributes negatively to the removal of the studied soil type. 
The above-mentioned work has shown that tank cleaning using pulsed flow offers an efficient approach to increase the usage efficiency of alkali solutions. Conventional burst cleaning practices can be further improved by shorting burst intervals and adding repetitions. The primary benefits of applying burst cleaning are to reduce cleaning costs and environmental footprint. However, caution should be taken when generating burst by frequent startup and shutdown of pumps, because surge pressures encountered when changing pump on-off status result in damages of centrifugal pumps and pipe systems. One solution to this problem is to equip a single seat valve with three body configurations (i.e. Alfa Laval Unique SSV Reverse Acting), which enables one flow channel to be closed while another channel is opened. As a result, the pump keeps running during the whole cleaning cycle, and the flow is switched between feeding and circulating. Another solution to protect facilities from frequent starting and stopping is to install variable frequency drive (VFD) for controlling the gradual acceleration and deceleration of pumps, which avoids the damage caused by sharp alteration of pump status.
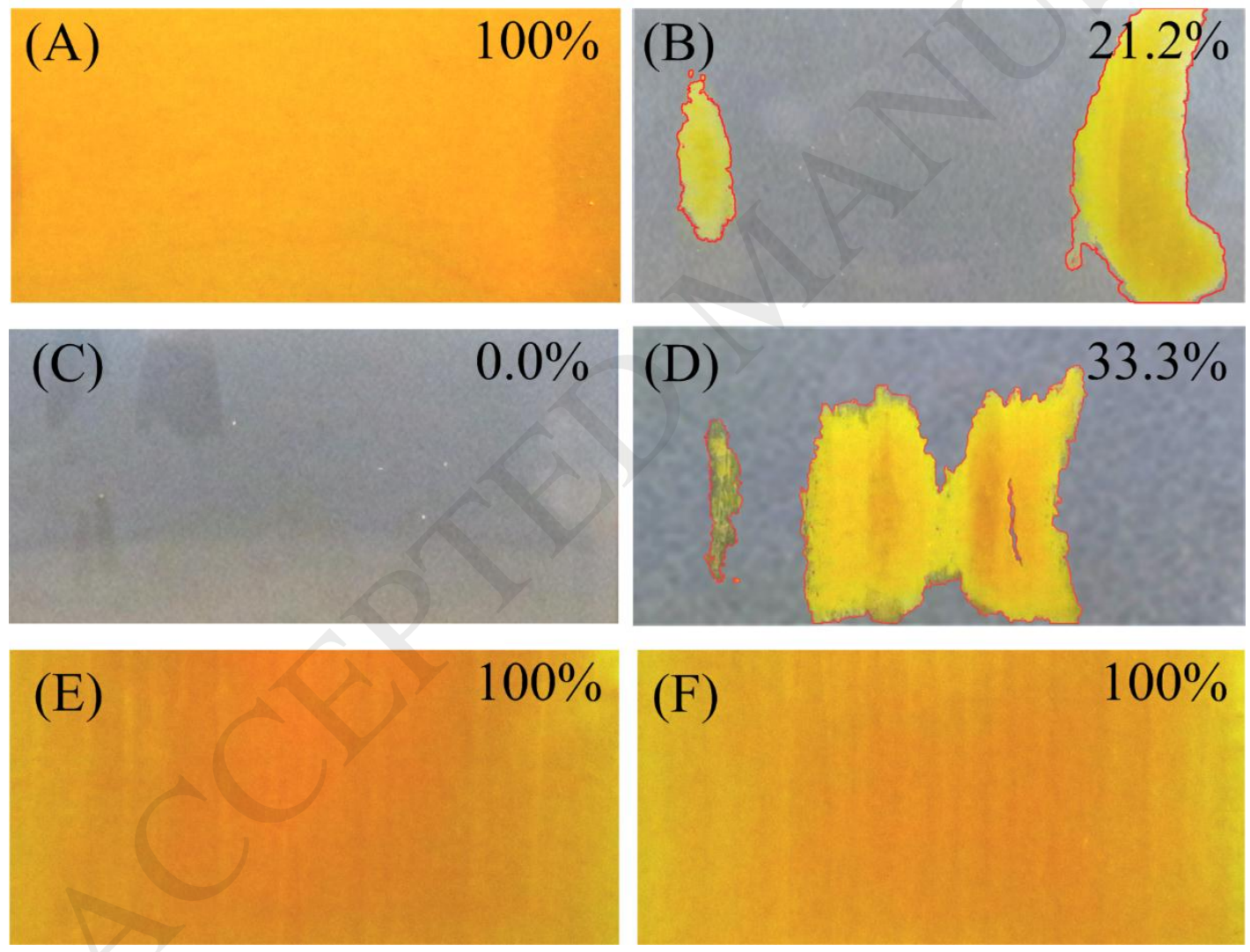

Figure 12 Photographs of the large scale test plate (only evaluated area of $55 \times 24 \mathrm{~cm}^{2}$ ) (A) before cleaning, and after cleaning by (B) continuous flow at $1 \mathrm{~kg} / \mathrm{m}^{3} \mathrm{NaOH}$, (C) pulsed flow at $1 \mathrm{~kg} / \mathrm{m}^{3} \mathrm{NaOH}$ with a period of $60 \mathrm{~s}$, (D) pulsed flow at $1 \mathrm{~kg} / \mathrm{m}^{3} \mathrm{NaOH}$ with a period of $2 \mathrm{~min}$, (E) continuous flow at $5 \mathrm{~kg} / \mathrm{m}^{3} \mathrm{NaOH}$, and (F) pulsed flow at $5 \mathrm{~kg} / \mathrm{m}^{3} \mathrm{NaOH}$ with a period of $60 \mathrm{~s}$. The photos are taken after 5 min of effective cleaning. The number on the upper right of each image indicates the percentage of soiling area, with ca. 10\% deviation. To highlight the remaining soils, images (B) and (D) have been processed by blurring the plate surface to remove noises due to lighting. 


\section{Conclusions}

This study investigated the potential of pulsed flow for improving the cleaning process of tank surfaces soiled by egg yolk layers, as well as the effects of different characteristics (process parameters: temperature, alkali concentration, flow rate; soiling situation: denaturation) on the cleaning results. The primary investigation was performed in pilot-scale, and the main findings were then examined in scale-up tests.

In the pilot-scale tests, the optimal conditions to remove egg yolk were low alkali concentration, high temperature and high flow rate. The interaction of alkali concentration with the other parameters affected the cleaning of the protein-based soiling material as well. For a given effective circulation time of alkali solution, the remaining soiling areas cleaned with continuous or pulsed flows could be expressed using a second-order regression model. Pulsed flow with high frequency resulted in more removal of soil deposit compared with that with low pulsing frequency. The enhancement by pulsed flow occurs primarily because additional holding time is provided for soil layers to swell. Then the materials become easy to remove in the next pulse of flow. Pre-wetting prior to continuous flow operation had no significant improvement of the cleaning result. It was found that cooking soiling materials above its denaturation temperature made the soil more difficult to be detached. Whereas, the enhanced cleaning behavior by applying pulsed flow became more obvious when removing cooked soils.

The main findings in pilot-scale were also found in scale-up tests. It was verified that the cleaning efficiency was highly improved by the pulsed flow with short period and high frequency. The negative contribution of high alkali concentration $\left(5 \mathrm{~kg} / \mathrm{m}^{3}\right)$ was still observed after scale-up. As a result, this work provided a quantitative measure to demonstrate that pulsed flow improves tank cleaning by reducing the relative consumption of cleaning detergent in order to achieve a certain cleanliness.

\section{Acknowledgement}

This project results from the DRIP (Danish partnership for Resource and water efficient Industrial food Production) project (http://drippartnership.com). We acknowledge that this work is partly funded by the Innovation Fund Denmark (IFD) under contract No. 5107-00003B, and by the Technical University of Denmark (DTU).

Appendix 


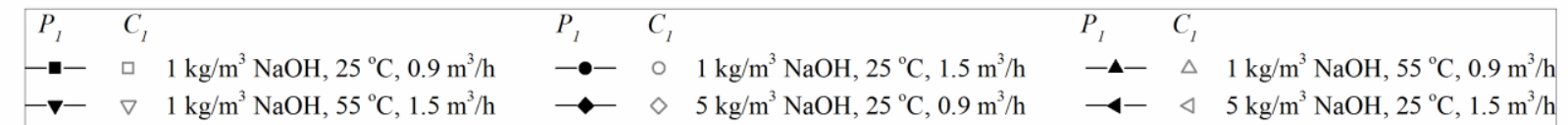

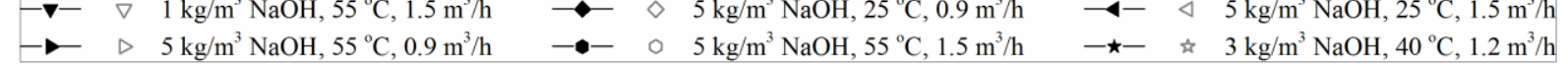

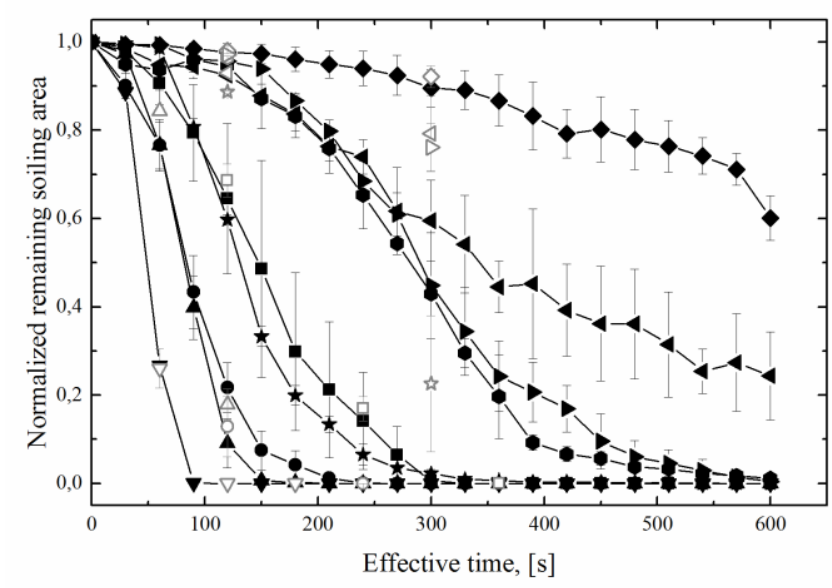

(A) Upper wall

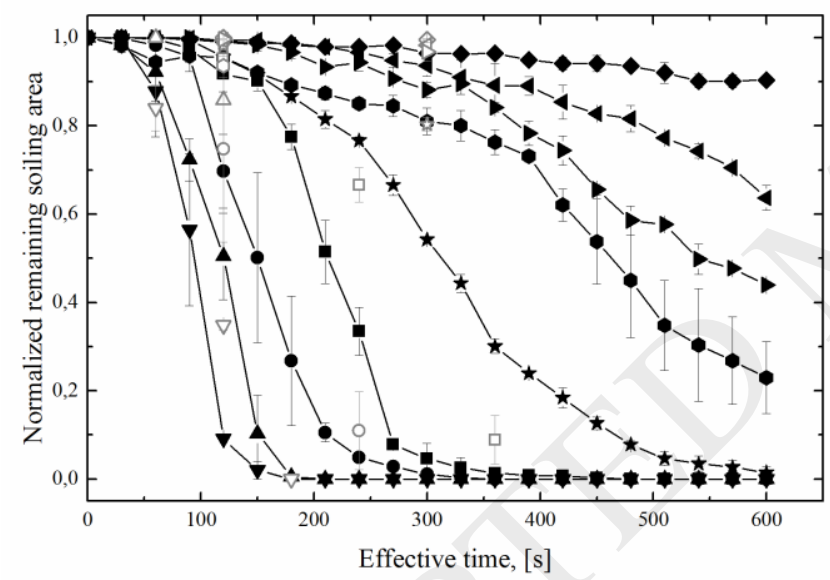

(C) Lower wall

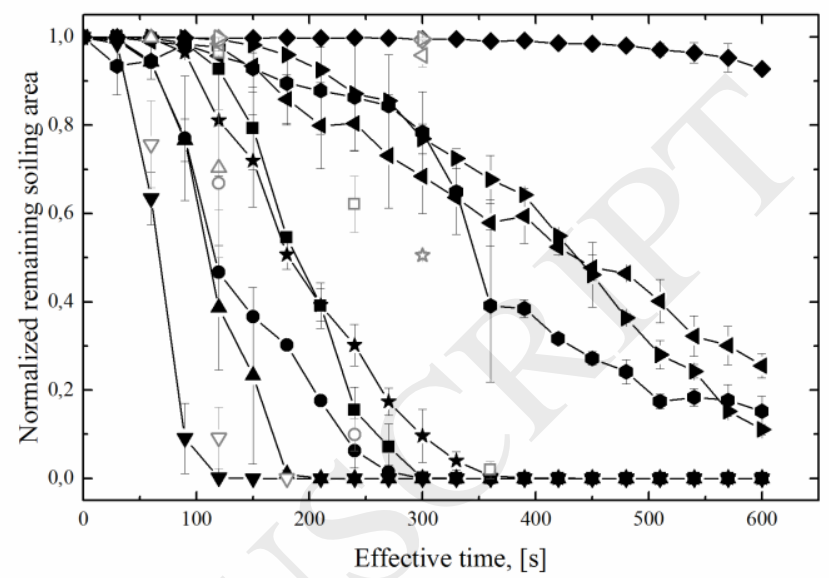

(B) Middle wall

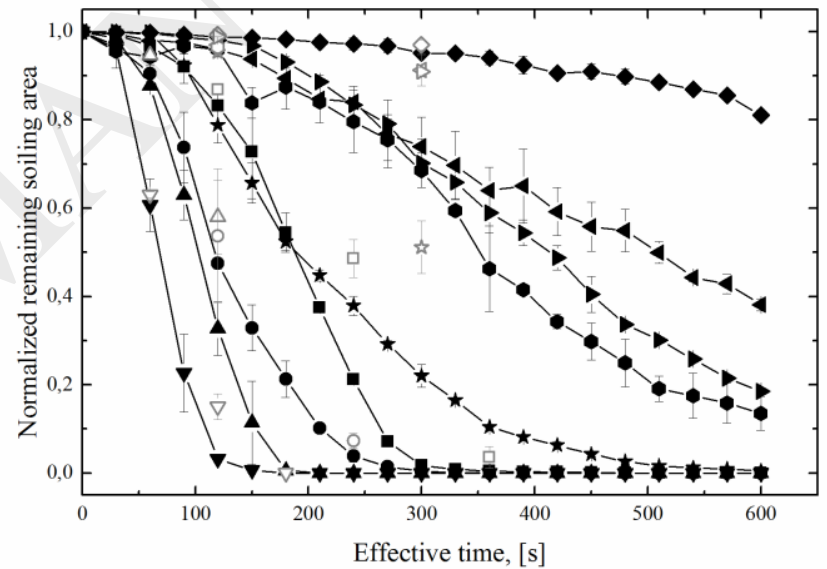

(D) Overall wall

Figure A1 Removal of uncooked soils for all runs under different conditions of temperature, flow rate and $\mathrm{NaOH}$ concentration, by using continuous flow without pre-wetting $\left(C_{l}\right)$ or pulsed flow in short period and high frequency $\left(P_{l}\right)$ : $(\mathrm{A})$ tank upper wall surface, $(\mathrm{B})$ tank middle wall surface, (C) tank lower wall surface, (D) tank overall wall surface.

\section{References}

Augustin, W., Fuchs, T., Föste, H., Schöler, M., Majschak, J.-P., Scholl, S., 2010. Pulsed Flow for Enhanced Cleaning in Food Processing. Food Bioprod. Process. 88, 384-391. doi:10.1016/j.fbp.2010.08.007

Bhagat, R.K., Perera, A.M., Wilson, D.I., 2017. Cleaning vessel walls by moving water jets: Simple models and 
supporting experiments. Food Bioprod. Process. 102, 31-54. doi:10.1016/j.fbp.2016.11.011

Bird, M.R., Fryer, P., 1992. An analytical model for the cleaning of food process plant, in: Food Engineering in a Computer Climate. CRC Press, pp. 325-330.

Bird, M.R., Fryer, P.J., 1991. An experimental study of the cleaning of surfaces fouled by whey proteins. Food Bioprod. Process. 69, 13-21.

Bode, K., Hooper, R.J., Paterson, W.R., Ian Wilson, D., Augustin, W., Scholl, S., 2005. Pulsed flow cleaning of whey protein fouling layers, in: Proceedings of 6th International Conference on Heat Exchanger Fouling and Cleaning - Challenges and Opportunities. The Berkeley Electronic Press, Kloster Irsee, Germany, pp. 165173. doi:10.1080/01457630601064611

Briggs, D.E., Boulton, C.A., Brookes, P.A., Stevens, R., 2004. Brewing: Science and Practice. CRC Press, Cambridge.

Celnik, M.S., Patel, M.J., Pore, M., Brahim, F., Augustin, W., Scholl, S., Scott, D.W., Wilson, D.I., 2005. Analytical approaches for calculation of shear stress enhancement in laminar pulsed flows, in: Proceedings of 6th International Conference on Heat Exchanger Fouling and Cleaning - Challenges and Opportunities. Kloster Irsee, pp. 174-182.

Christian, G.K., Fryer, P.J., 2006. The Effect of Pulsing Cleaning Chemicals on the Cleaning of Whey Protein Deposits. Food Bioprod. Process. 84, 320-328. doi:10.1205/fbp06039

Denmat, M. Le, Anton, M., Gandemer, G., 1999. Protein Denaturation and Emulsifying Properties of Plasma and Granules of Egg Yolk as Related to Heat Treatment. J. Food Sci. 64, 194-197. doi:10.1111/j.13652621.1999.tb15863.x

Feldung Damkjær, N., Adler-Nissen, J., Jensen, B.B.B., Wilson, D.I., 2017. Flow pattern and cleaning performance of a stationary liquid jet operating at conditions relevant for industrial tank cleaning. Food Bioprod. Process. 101, 145-156. doi:10.1016/j.fbp.2016.11.001

Föste, H., Schöler, M., Majschak, J.-P., Augustin, W., Scholl, S., 2013. Modeling and Validation of the Mechanism of Pulsed Flow Cleaning. Heat Transf. Eng. 34, 753-760. doi:10.1080/01457632.2012.741499

Fryer, P.J., Robbins, P.T., Asteriadou, K., 2011. Current knowledge in hygienic design: can we minimize fouling and speed cleaning? Procedia Food Sci. 1, 1753-1760. doi:10.1016/j.profoo.2011.09.258 
Fuchs, E., Helbig, M., Pfister, M., Majschak, J.-P., 2017. Erhöhung der Reinigungseffizienz bei der Cleaning-inPlace-Reinigung durch diskontinuierliche Flüssigkeitsstrahlen. Chemie Ing. Tech. 89, 1072-1082. doi:10.1002/cite.201600105

Gillham, C.R., Fryer, P.J., Hasting, A.P.M., Wilson, D.I., 2000. Enhanced cleaning of whey protein soils using pulsed flows. J. Food Eng. 46, 199-209. doi:10.1016/S0260-8774(00)00083-2

Goode, K.R., Asteriadou, K., Fryer, P.J., Picksley, M., Robbins, P.T., 2010. Characterising the cleaning mechanisms of yeast and the implications for Cleaning In Place (CIP). Food Bioprod. Process. 88, 365-374. doi:10.1016/j.fbp.2010.08.005

Goode, K.R., Asteriadou, K., Robbins, P.T., Fryer, P.J., 2013. Fouling and Cleaning Studies in the Food and Beverage Industry Classified by Cleaning Type. Compr. Rev. Food Sci. Food Saf. 12, 121-143. doi:10.1111/1541-4337.12000

Gordon, P.W., Brooker, A.D.M., Chew, Y.M.J., Letzelter, N., York, D.W., Wilson, D.I., 2012. Elucidating enzyme-based cleaning of protein soils (gelatine and egg yolk) using a scanning fluid dynamic gauge. Chem. Eng. Res. Des. 90, 162-171. doi:10.1016/J.CHERD.2011.07.007

Helbig, M., Zahn, S., Böttcher, K., Rohm, H., Majschak, J.-P., 2018. Laboratory Methods to predict the cleaning behaviour in a flow channel exemplified by egg yolk layer, in: Foulig and Cleaning in Food Processing 2018. Lund, Sweden, pp. 149-166.

Jensen, B.B.B., 2007. Improving the cleaning effect by changing average velocity. Trends Food Sci. Technol. 18, S58-S63.

Kjellberg, K., 2016. Rotary jet head 'burst' cleaning technology delivers significant savings in cleaning costs. EHEDG Yearb. 2015/2016 96-98.

Lerch, K., Hinrichs, J., Dittmer, P., Rauschnabel, J., 2013. Cleanability of Surfaces from Active Pharmaceutical Ingredient Surrogate Riboflavin by Falling Film. Chemie Ing. Tech. 85, 323-332. doi:10.1002/cite.201100207

Montgomery, D.C., 2012. Design and Analysis of Experiments, 8th ed. John Wiley \& Sons, Inc. doi:10.1198/tech.2006.s372

Olayiwola, B., Walzel, P., 2009. Effects of in-phase oscillation of retentate and filtrate in crossflow filtration at 
low Reynolds number. J. Memb. Sci. 345, 36-46. doi:10.1016/j.memsci.2009.08.022

Palabiyik, I., Yilmaz, M.T., Fryer, P.J., Robbins, P.T., Toker, Ö.S., 2015. Minimising the environmental footprint of industrial-scaled cleaning processes by optimisation of a novel clean-in-place system protocol. J. Clean. Prod. 108, 1009-1018. doi:10.1016/j.jclepro.2015.07.114

Perez-Mohedano, R., Letzelter, N., Bakalis, S., 2016. Swelling and hydration studies on egg yolk samples via scanning fluid dynamic gauge and gravimetric tests. J. Food Eng. 169, 101-113. doi:10.1016/J.JFOODENG.2015.08.014

Stenby, M., Dethlefsen, M.W., Jensen, B.B.B., 2012. New test method for rotating spray head performance in tank cleaning. J. Hyg. Eng. Des. 1, 40-43.

Stoye, H., Köhler, H., Mauermann, M., Majschak, J.-P., 2014. Untersuchungen zur Steigerung der Reinigungseffizienz durch pulsierende Spritzreinigung. Chemie Ing. Tech. 86, 707-713. doi:10.1002/cite. 201300047

Tamime, A.Y., 2008. Cleaning-in-Place: Dairy, Food and Beverage Operations, 3rd ed. Blackwell, Ayr, UK.

Tihon, J., Serifi, K., Argyriadi, K., Bontozoglou, V., 2006. Solitary waves on inclined films: Their characteristics and the effects on wall shear stress. Exp. Fluids 41, 79-89. doi:10.1007/s00348-006-0158-1

Tihon, J., Tovchigrechko, V., Sobolík, V., Wein, O., 2003. Electrodiffusion detection of the near-wall flow reversal in liquid films at the regime of solitary waves. J. Appl. Electrochem. 33, 577-587. doi:10.1023/A:1024988602276

Tukker, A., Huppes, G., Guinée, J., Heijungs, R., Koning, A. de, Oers, L. van, Suh, S., Geerken, T., Holderbeke, M. Van, Jansen, B., Nielsen, P., 2006. Environmental Impact of Products (EIPRO): Analysis of the life cycle environmental impacts related to the final consumption of the EU25.

Weidemann, C., Vogt, S., Nirschl, H., 2014. Cleaning of filter media by pulsed flow - establishment of dimensionless operation numbers describing the cleaning result. J. Food Eng. 132, 29-38. doi:10.1016/j.jfoodeng.2014.02.005

Yang, J., Jensen, B.B.B., Nordkvist, M., Rasmussen, P., Gernaey, K. V., Krühne, U., 2018. CFD modelling of axial mixing in the intermediate and final rinses of cleaning-in-place procedures of straight pipes. J. Food Eng. 221, 95-105. doi:10.1016/j.jfoodeng.2017.09.017 


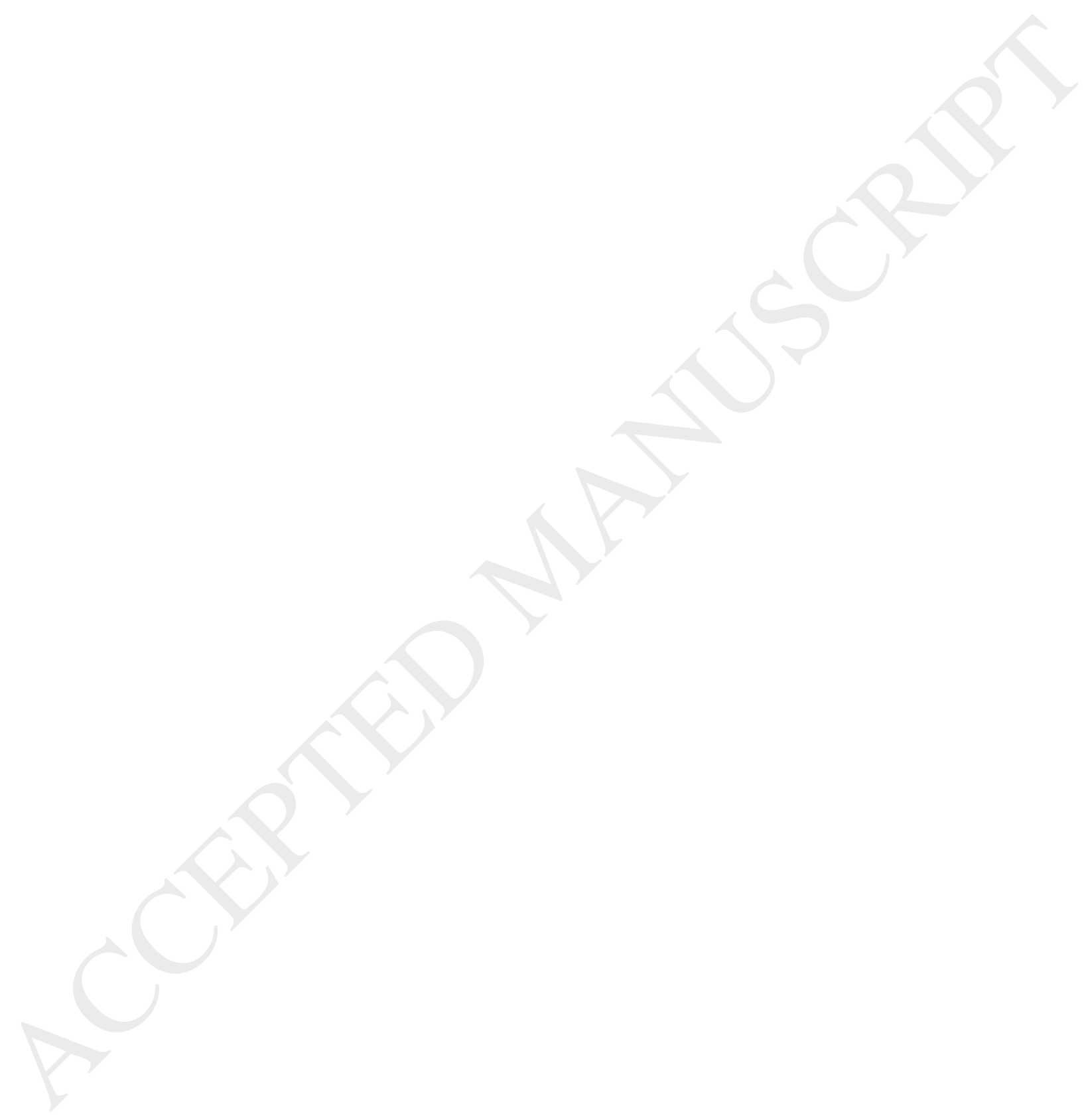

Page 31 of $\mathbf{3 1}$ 